\title{
CXCL11-CXCR3 Axis Mediates Tumor Lymphatic Cross Talk and Inflammation-Induced Tumor, Promoting Pathways in Head and Neck Cancers
}

Subhashree Kumaravel, * Sumeet Singh, * Sukanya Roy, ${ }^{*}$ Lavanya Venkatasamy, ${ }^{*}$ Tori K. White, * Samiran Sinha, Shannon S. Glaser, * Stephen H. Safe, ${ }^{\ddagger}$ and Sanjukta Chakraborty*

From the Department of Medical Physiology,* Texas A\&M Health Science Center College of Medicine, Bryan; and the Departments of Statistics ${ }^{\dagger}$ and Veterinary Physiology and Pharmacology, ${ }^{\ddagger}$ Texas A\&M University, College Station, Texas

Accepted for publication

December 19, 2019.

Address correspondence to Sanjukta Chakraborty, Ph.D., Medical Physiology, College of Medicine, Texas A\&M University, 2416 Medical Research Building II, 8447 Riverside Parkway, Bryan, TX 77807. E-mail:

schakraborty@tamu.edu.

\begin{abstract}
Tumor metastasis to the draining lymph nodes is critical in patient prognosis and is tightly regulated by molecular interactions mediated by lymphatic endothelial cells (LECs). The underlying mechanisms remain undefined in the head and neck squamous cell carcinomas (HNSCCs). Using HNSCC cells and LECs we determined the mechanisms mediating tumor-lymphatic cross talk. The effects of a pentacyclic triterpenoid, methyl 2-trifluoromethyl-3,11-dioxoolean-1,12-dien-30-oate ( $\left.\mathrm{CF}_{3} \mathrm{DODA}-\mathrm{Me}\right)$, a potent anticancer agent, were studied on cancer-lymphatic interactions. In response to inflammation, LECs induced the chemokine ( $C-X-C$ motif) ligand $9 / 10 / 11$ chemokines with a concomitant increase in the chemokine ( $\mathrm{C}-\mathrm{X}-\mathrm{C}$ motif) receptor 3 (CXCR3) in tumor cells. $\mathrm{CF}_{3} \mathrm{DODA}-$ Me showed antiproliferative effects on tumor cells, altered cellular bioenergetics, suppressed matrix metalloproteinases and chemokine receptors, and the induction of CXCL11-CXCR3 axis and phosphatidylinositol 3-kinase/AKT pathways. Tumor cell migration to LECs was inhibited by blocking CXCL11 whereas recombinant CXCL11 significantly induced tumor migration, epithelial-to-mesenchymal transition, and matrix remodeling. Immunohistochemical analysis of HNSCC tumor arrays showed enhanced expression of CXCR3 and increased lymphatic vessel infiltration. Furthermore, The Cancer Genome Atlas RNA-sequencing data from HNSCC patients also showed a positive correlation between CXCR3 expression and lymphovascular invasion. Collectively, our data suggest a novel mechanism for cross talk between the LECs and HNSCC tumors through the CXCR3-CXCL11 axis and elucidate the role of the triterpenoid CF $_{3}$ DODA-Me in abrogating several of these tumor-promoting pathways. (Am J Pathol 2020, 190: 900-915; https:// doi.org/10.1016/j.ajpath.2019.12.004)
\end{abstract}

Lymph node metastasis has been directly associated with aggressive disease and poor patient outcome in multiple cancers. $^{1,2}$ Head and neck squamous cell carcinoma (HNSCC) is the sixth most common cancer worldwide and includes tumors of the oral cavity, paranasal sinuses, nasal cavity, pharynx, and larynx. ${ }^{3}$ Squamous cell carcinomas account for approximately $90 \%$ of all head and neck cancers and are formed in the mucosal lining of these regions. Recurrent or metastatic HNSCC displays frequent metastasis to lymph nodes and is associated with a 5-year survival rate of $<50 \%$.,

In HNSCC, intratumoral lymphatics are reported to aid nodal metastasis, resulting in local relapse of tumor. ${ }^{6}$
Accumulating evidence clearly points to an active role played by the lymphatic endothelium in regulating tumor entry and migration to the draining lymph nodes. ${ }^{7,8}$ Previous reports have suggested that lymphatic endothelial cells (LECs) in tumor-associated lymphatic vessels display altered phenotypes and secrete or express several specific chemokines or chemokine receptors that define a tissue-

Supported by Texas A\&M University Health Science Center Auf-XGrant Award (S.C.), American Heart Association grant 17SDG33670306 (S.C.), and NIH grants DK110035 (S.G.) and P30-ES023512 (S.S.).

Disclosures: None declared. 
specific pattern of metastatic spread. ${ }^{5,9}$ Tumor cells, on the other hand, are engaged in this bidirectional cross talk and co-opt several pathways that are normally used by immune cells to traffic through lymphatics and lymph nodes. ${ }^{10-12}$ Several chemokine/chemokine receptor pairs, such as chemokine (C-C motif) receptor 7 (CCR7)/chemokine (C-C motif) ligand 21 , chemokine (C-C motif) receptor 4 (CXCR4)/CXCL12, and chemokine (C-C motif) receptor 8 (CCR8)/chemokine (C-C motif) ligand 1, mediate tumor lymphatic cross talk. ${ }^{13,14}$ However, these pathways are not clearly defined for HNSCC tumors. The chemokine (C-X-C motif) ligands 9,10,11 (CXCL9/10/11)-chemokine (C-C motif) receptor 3 (CXCR3) signaling axis is a promising target for drug development by activating the paracrine axis that enhances immune activation and inhibiting the autocrine axis that regulates promotion of tumor growth and metastasis. ${ }^{15}$ Because of the highly metastatic nature of HNSCC, several combination therapies are used to enhance antitumor activity. ${ }^{16,17}$ However, a major factor complicating therapeutic regimens is that tumors in different microenvironments respond differently, depending on the cues from their surrounding milieu. ${ }^{18}$ These scenarios warrant identification of new compounds to treat HNSCC by inhibiting pathways that promote tumor progression and migration and inhibit local and distant metastasis by inhibiting tumor entry into lymphatics. Several structural classes of triterpenoids, including betulinic acid, bardoxolone derivatives, and structurally related glycyrrhetinic acid derivatives, have been extensively investigated as anticancer agents. ${ }^{19-21}$ These compounds inhibit cancer cell migration and invasion; however, their effects on signaling pathways that are important for the tumor-lymphatic cross talk are unknown. In this study, we have used the glycyrrhetic acid derivative, methyl 2-trifluoromethyl-3, 11-dioxo-18-olean1,12-dien-30-oate $\left(\mathrm{CF}_{3} \mathrm{DODA}-\mathrm{Me}\right)$, as a model triterpenoid for investigating effects on tumor lymphatic cross talk.

This study had two primary goals: delineating the molecular cross talk between LECs and the head and neck tumor cells that induce tumor chemoattraction toward lymphatics, causing activation of tumor-promoting mechanisms, and investigating the efficacy of $\mathrm{CF}_{3} \mathrm{DODA}-\mathrm{Me}$ on LEC-mediated tumor chemoattraction and signaling mechanisms. These studies demonstrate that the CXCL11/ CXCR3 axis plays an important role in LEC-tumor cross talk and activates several tumor-promoting pathways. $\mathrm{CF}_{3}$ DODA-Me exhibits significant antitumor effects and inhibits several of these key pathways.

\section{Materials and Methods}

\section{Ethics Statement}

All experiments were performed in accordance with policies and approval of Texas A\&M University (College Station, TX) Institutional Biosafety Committee.

\section{Cell Culture and Compound Treatment}

Head and neck cancer cell lines SCC-9, FADU, and Detroit 562 were directly purchased from ATCC (Manassas, VA). SCC-9 was grown in Dulbecco's modified Eagle's medium (DMEM)-F12 medium supplemented with $10 \%$ fetal bovine serum (FBS), $400 \mathrm{ng}$ hydrocortisone, and 1\% penicillin/streptomycin, as recommended. FADU and Detroit 562 were grown in modified Eagle's medium supplemented with 10\% FBS. Human LECs were obtained from Promocell (Heidelberg, Germany) and grown in complete endothelial growth medium (EGM-MV2; Promocell), as previously described. ${ }^{22}$ The cells were maintained at $37^{\circ} \mathrm{C}$ in a humidified atmosphere of $5 \% \mathrm{CO}_{2}$ and routinely verified for lymphatic-specific markers lymphatic vessel endothelial hyaluronan receptor 1 (LYVE1), prospero homeobox 1 (PROX1), and podoplanin (data not shown). LEC conditioned medium (LEC-CM) was prepared by growing cells in EGM-MV2 (without any growth factors) for 48 hours. Lipopolysaccharide (LPS; $100 \mathrm{ng} / \mathrm{mL}$ ), obtained from Sigma Aldrich (St. Louis, MO), was used for inducing the inflammatory response in the LECs, as described previously. ${ }^{23}$ For LPS-primed LEC conditioned medium (LPSLEC-CM), LECs were treated with LPS $(100 \mathrm{ng} / \mathrm{mL})$ for 24 hours. The culture medium was then removed and replaced with EGM-MV2 (without any growth factors) and left for another 48 hours. The culture supernatant was then collected and centrifuged $(1000 \times g, 5$ minutes $)$ and either used immediately or stored at $-80{ }^{\circ} \mathrm{C}$ for later use. $\mathrm{CF}_{3}$ DODAMe was synthesized, as described. ${ }^{24}$ Dimethyl sulfoxide was used as vehicle control. All other chemicals and reagents were from Sigma Aldrich unlessotherwise stated.

\section{Cell Proliferation Assay}

HNSCC cells were plated in 12-well plates. At 70\% confluency, the cells were primed with LEC-CM or LPS-LEC$\mathrm{CM}$ for 24 hours. Cells were then treated with varying concentrations of $\mathrm{CF}_{3}$ DODA-Me $(1,2$, and $5 \mu \mathrm{mol} / \mathrm{L})$ for 24 hours, as described before. ${ }^{24}$ Cells were then trypsinized, and cell proliferation was determined by counting cells using the Countess II Automated Cell Counter (Thermo Fisher Scientific, Waltham, MA), as previously described. ${ }^{25}$

\section{Seahorse Assay}

The mitochondrial respiration and glycolysis of SCC-9 in response to LEC-CM, LPS-LEC-CM, and $\mathrm{CF}_{3}$ DODA-Me were assessed using the Seahorse XFp Cell Energy Phenotype Test Kit (Agilent Technologies, Santa Clara, CA) in Seahorse XFe96 extracellular flux analyzer, according to manufacturer's instructions. Briefly, $5 \times 10^{4}$ cells were plated per well in $\mathrm{XFe} 96$ plates and incubated with complete DMEM/F12 cell culture medium in $5 \% \mathrm{CO}_{2}$ atmosphere at $37^{\circ} \mathrm{C}$ for 24 hours. The medium was then changed to 5\% FBS containing EGM-MV2, LEC-CM, or 
LPS-LEC-CM and left for 24 hours. Then, $\mathrm{CF}_{3}$ DODA-Me was added at 2 or $5 \mu \mathrm{mol} / \mathrm{L}$ concentration while the control groups received dimethyl sulfoxide. After 24 hours, the medium was replaced with unbuffered DMEM XF assay medium ( $\mathrm{pH}$ adjusted to 7.4 using $1 \mathrm{~N}$ sodium hydroxide) supplemented with $2 \mathrm{mmol} / \mathrm{L}$ glutamine and $1 \mathrm{~g} / \mathrm{L}$ glucose. The cells were placed in a $37^{\circ} \mathrm{C} \mathrm{CO}_{2}$-free incubator for 1 hour. The basal oxygen consumption rate (OCR) and extracellular acidification rate (ECAR) were then determined using the XFe96 plate reader using Wave software version 2.1.6 (Agilent Technologies), as recommended by the manufacturer. The OCR at time points before oligomycin injection is associated with basal respiration and postFCCP [carbonyl cyanide-4 (trifluoromethoxy) phenylhydrazone] injection is associated with maximal respiration. The ECAR at time points before oligomycin injection is associated with glycolysis and post-oligomycin injection is associated with maximal glycolytic capacity. ${ }^{26,27}$ After establishing a baseline for 18 minutes, OCR, ECAR, or metabolic potential of all the groups, on the basis of stressed OCR and stressed ECAR percentage, was monitored for 48 minutes. Results were normalized by staining cells using CyqQUANT cell proliferation assay kit (Thermo Fisher Scientific). ${ }^{28}$ Data were analyzed using the GraphPad Prism software version 8.0.0 (GraphPad Software Inc., San Diego, CA).

\section{Apoptosis Assay}

HNSCC cells were grown in a 12-well plate. At $70 \%$ confluency, the cells were treated with or without LEC-CM and LPS-LEC-CM for 24 hours. Cells were then treated with 1, 2 , and $5 \mu \mathrm{mol} / \mathrm{L}$ of $\mathrm{CF}_{3}$ DODA-Me for 24 hours. Apoptosis assay was performed using Annexin V-FITC Apoptosis Detection Kit (Sigma Aldrich). Briefly, the cells were washed with phosphate-buffered saline trypsinized and binding buffer containing Annexin V-FITC conjugate was added and incubated for 10 minutes. Percentages of cells stained with Annexin V-FITC were obtained with the Countess II Automated Cell Counter (Thermo Fisher Scientific).

\section{Migration Assay}

Migration of SCC-9, FADU, and Detroit 562 was assessed by plating $1 \times 10^{5}$ cells in $8.0-\mu \mathrm{m}$ pore PTE standing inserts (Millipore, Burlington, MA) placed in a 24-well plate. LECs were plated in the wells of the 24-well plate and EGM-MV2 medium containing 3\% FBS (3\% EGM-MV2) was used for both inserts and lower chambers. For analyzing LEC migration, $1 \times 10^{5}$ LECs were plated in $8.0-\mu \mathrm{m}$ pore PTE standing inserts (Millipore) that were coated with $50 \mu \mathrm{g} / \mathrm{mL}$ of collagen. LECs were then allowed to migrate for 24 hours toward SCC-9, FADU, or Detroit 562. For analyzing the effect of $\mathrm{CF}_{3}$ DODA-Me on SCC-9 or LEC migration, the cells were treated with or without $\mathrm{CF}_{3}$ DODA-Me $(1,2$, or 5 $\mu \mathrm{mol} / \mathrm{L}$ ) for 24 hours. For CXCR3 blocking, SCC-9 cells were treated with AMG487 ( $1 \mu \mathrm{mol} / \mathrm{L}$; Tocris Bioscience, Bristol, UK) for 24 hours. For inducing inflammatory response in the LECs, they were treated with $100 \mathrm{ng} / \mathrm{mL}$ of LPS for 24 hours before placement of inserts with SCC-9. For CXCL11 inhibition, $1 \mu \mathrm{g} / \mathrm{mL}$ of CXCL11 neutralizing antibody (R\&D Systems, Minneapolis, MN) was added to the LPS-treated LECs for the duration of the experiment. In other experiments, to analyze the chemotactic role of CXCL11 on SCC-9 cell migration, CXCL11 recombinant protein $(100 \mathrm{ng} / \mathrm{mL}$; R\&D Systems) was added to the wells in plain DMEM-F12 medium. SCC-9 cells were trypsinized, resuspended in plain DMEM or 3\% EGM-MV2, and allowed to migrate toward DMEM-F12 with 10\% FBS medium, LECs, or CXCL11 for 24 hours.

The inserts were washed with Dulbecco's phosphatebuffered saline, fixed with ice-cold methanol, and stained with $0.5 \%$ crystal violet. Images were captured at $\times 10$ magnification from five different fields using an inverted microscope (Nikon, Melville, NY). The number of cells was counted using the ImageJ software version 1.52a $(\mathrm{NIH}$, Bethesda, MD; https://imagej.nih.gov/ij).

\section{Cell Lysis and Western Blot Analysis}

SCC-9 cells were treated with $\mathrm{CF}_{3}$ DODA-Me with or without LPS-LEC-CM or CXCL11 recombinant protein (100 ng/mL) for 24 hours. LECs were treated with LPS and then treated with compounds, as described above. Cells were lysed using M-PER protein extraction buffer (Thermo Fisher Scientific, Waltham, MA) and then sonicated. Protein was quantified using Pierce BCA Protein Assay Kit (Thermo Fisher Scientific). Proteins were separated using Bolt $4 \%$ to $12 \%$ Bis-Tris gel (Invitrogen, Thermo Fisher Scientific) and transferred onto a nitrocellulose membrane (Invitrogen) and probed with antibodies to phosphorylated AKT, AKT, phosphorylated STAT-3 (p-STAT-3), STAT-3, phosphorylated Janus kinase-2 (p-JAK-2), Janus Kinase 2 (JAK-2), phosphorylated extracellular signal-regulated kinase $1 / 2$ (p-ERK1/2), ERK1/2, and $\beta$-actin (Cell Signaling Technology, Danvers, MA). After incubation with the corresponding secondary antibody, proteins were visualized with the Chemiluminescence Detection kit (Pierce, Thermo Fisher Scientific) and imaged with ImageQuant LAS 4000 system (GE Healthcare, Life Sciences, Chicago, IL). The densitometric analysis of bands was performed with Image $\mathrm{J}$ software version $1.52 \mathrm{a}$, as described previously. ${ }^{21}$

\section{RNA Isolation and Real-Time PCR}

Total RNA was extracted from cells after different treatments, as described above, using the Purelink RNA mini kit (Thermo Fisher Scientific; according to the manufacturer's instructions). The quality and quantity of RNA were determined using a Nanodrop (NanoDrop Technologies, 
Wilmington, DE), and cDNA was prepared as described. ${ }^{22}$ Real-time PCR was performed for inflammatory markers, cytokines, chemokines, matrix metalloproteinases (MMPs), and epithelial-to-mesenchymal transition (EMT) markers using SYBR Green (Applied Biosystems, Foster City, CA) in a real-time thermal cycler (ABI Prism 7900HT sequence detection system; Applied Biosystems). All reactions were performed in triplicate. Primer sets (Sigma-Aldrich) used to test the expression of candidate genes are listed in Table 1. Data were analyzed using the $2^{-\Delta \Delta \mathrm{Ct}}$ method, ${ }^{22}$ where ubiquitin was used as the reference gene.

\section{ELISA Assay for CXCL11}

LECs were plated in 12-well plates and treated with CM from SCC-9, FADU, Detroit 562, or LPS (100 ng/mL) for 24 hours, as described above. The medium was then replaced with EGM-MV2, and conditioned medium was collected from the primed LECs after 48 hours. Enzymelinked immunosorbent assay (ELISA) was performed using the Human CXCL11/I-TAC Quantikine ELISA Kit (R\&D Systems, Minneapolis, MN), according to manufacturer's instructions. Values were represented as $\mathrm{pg} / \mathrm{mL}$.

\section{Immunohistochemistry}

Expression of CXCR3 and podoplanin was assessed in commercially available paraffin-embedded deidentified HNSCC tumor section arrays containing a total of 70 cases of HNSCC and 10 normal tissues (Biomax US, Derwood, MD). For detecting CXCR3 expression, deparaffinization, antigen retrieval, and immunohistochemical staining with CXCR3 antibody (1:500; Abcam, Cambridge, UK) steps were performed. Fluorescent detection was performed with Alexa Fluor 488, and images were captured using $20 \times$ objective (Olympus, Tokyo, Japan). For podoplanin, immunohistochemistry was performed, as described previously. ${ }^{29}$ Briefly, deparaffinized, antigen-retrieved array sections were incubated with primary mouse anti-human podoplanin and cytokeratin 19 antibodies and secondary biotinylated antibody (LSAB Plus System-HRP; Dako Cytomation, Glostrup, Denmark), then with Dako ABC for 20 minutes, and developed with 3,3'-diaminobenzidine (Dako Cytomation Liquid DAB Plus Substrate Chromogen System). Images were captured using $20 \times$ objective (Olympus). Semiquantitative analysis of positive staining was performed, as previously described. ${ }^{13}$

Table 1 Primer Sequences Used for Real-Time PCR

\begin{tabular}{|c|c|c|}
\hline Primer & Forward sequence & Reverse sequence \\
\hline CCR1 & $5^{\prime}$-CACGGACAAAGTCCCTTGGA-3' & 5'-TGTGGTCGTGTCATAGTCCTCTGT-3' \\
\hline CCR2 & 5'-GCCTTTTTCACATAGCTCTTGGC-3' & 5'-AGGAGTCCTTGTGTAGTCACTTT-3' \\
\hline CCR8 & 5'-ATGCCGTGTATGCCCTAAAG- $3^{\prime}$ & 5'-GCCTTGGTCTTGTTGTGGTT-3' \\
\hline CXCR1 & 5'-CTGTTCTGCTACGTGGAGATCC-3' & 5'-CAGGGCGTATTCTAGCTGCTG-3' \\
\hline CXCR3 & $5^{\prime}$-СTCTGCTGGACCCCСТATCA-3' & $5^{\prime}$-GTCTCAGACCAGGATGAATC-3' \\
\hline CCL19 & 5'-ATGTGAATCACTCTGGCCCAGGAA-3' & 5'-AAGCGGCTTTATTGGAAGCTCTGC-3' \\
\hline CXCL9 & 5'-TTTTCCTCTTGGGCATCATC-3' & 5'-GAACAGCGACCCTTTCTCAC-3' \\
\hline CXCL10 & $5^{\prime}$-GAGCCTACAGCAGAGGAACC-3' & $5^{\prime}$-GAGTCAGAAAGATAAGGCAGC - $3^{\prime}$ \\
\hline CXCL11 & 5'-GCTGTGATATTGTGTGCTACAGT-3' & 5'-GCTTCGATTTGGGATTTAGGCA-3' \\
\hline GLI1 & 5'-AGGGCTGCAGTAAAGCCTTCA-3' & 5'-CTTGACATCTTTTCGCAGCG-3' \\
\hline MMP2 & 5'-GCTGGCTGCCTTAGAACCTTTC-3' & 5'-GAACCATCACTATGTGGGCTGAGA-3' \\
\hline MMP7 & 5'-GGGACATTCCTCTGATCCTAATGC-3' & 5'-GAATTACTTCTCTTTCCATATCGTTTCTGAATGC-3' \\
\hline MMP9 & $5^{\prime}$-GCACGACGTCTTCCAGTACC- $3^{\prime}$ & $5^{\prime}$-GCACTGCAGGATGTCATAGGT-3' \\
\hline MMP11 & 5'-CAАCATACСТCААТССТGTCCC-3' & 5'-CAATGGCTTTGGAGGATAGC- $3^{\prime}$ \\
\hline MMP12 & 5'-TTGAATATGACTTCCTACTCCAACG-3' & 5'-GTGGTACACTGAGGACATAGCAAAT-3' \\
\hline MMP21 & $5^{\prime}$-AACAATAGGACACGCTATGG- $3^{\prime}$ & 5'-CATCTCTTTTCCATGTCCAG-3' \\
\hline PTCH1 & $5^{\prime}-$ TGAGACTGACCACGGCCTG-3' & $5^{\prime}$-ACCCTCAGTTGGAGCTGCTTG-3' \\
\hline SNAI2 & $5^{\prime}$-ACATTAGAACTCACACGGGGA-3' & 5'-GTGTGCTACACAGCAGCCAGA-3' \\
\hline TGFB2 & 5'-AGTGGACATCAACGGGTTCAG-3' & $5^{\prime}-$ CATGAGAAGCAGGAAAGGCC- $3^{\prime}$ \\
\hline TWIST1 & 5'-GGCTCAGCTACGCCTTCTC-3' & 5'-TCCTTCTCTGGAAACAATGACA-3' \\
\hline TWIST2 & $5^{\prime}$ - AGCGACGAGATGGACAATAAGATGACC-3' & 5'-CGGTCCGGAGGTGGGTGGCG-3' \\
\hline
\end{tabular}


TCGA Database Analysis of CXCR3 Expression in HNSCC Patient Samples

HNSCC tumor data were obtained from The Cancer Genome Atlas (TCGA), which provides a wide spectrum of genomic, molecular, and clinical features. Using the $\mathrm{R}$ package TCGA2STAT, the aggregated level 3 data available at the Broad Institute GDAC Firehose was downloaded. In particular, the normalized counts in reads per kilobase of transcript, per million mapped reads (RPKM) RNA-sequencing data, measured via the Illumina HiSeq 2000 profiling method, were downloaded for gene CXCR3 for 520 patients. Along with that, the corresponding clinical variables, such as sex, age of diagnosis, pathologic stage, and pathologically determined absence, presence, or extent of regional lymph node metastasis, as defined by the American Joint Committee on Cancer (coded as ajcc_nodes_pathologic_pn), were also downloaded. The expression data were $\log 2$ transformed after adding a small constant of 0.1 with the expression. Pathologic stage was available for only 448 subjects. Because of low patient numbers, the stage variable was reclassified into three categories, stages I, II, and combined stages III and IV. The pathologically determined lymph node metastasis was also categorized as yes and no, and referred to as LNM. To determine any association of CXCR3 expression with clinical parameters, a multinomial logistic model and a likelihood ratio test were used.

\section{Statistical Analysis}

All experiments were performed at a minimum in triplicate. Mean values of different treatment groups were compared statistically using analysis of variance, followed by Fisher least significant difference tests or using $t$-tests with GraphPad Prism software, as appropriate. Values are represented as means \pm SEM. Groups were identified as significantly different if $P \leq 0.05$.

\section{Results}

\section{HNSCC Cell Lines Show Increased Migration and Chemoattraction in Response to LECs and Vice Versa}

Interaction between LECs and tumor cells is the first step during the process of LNM. Here, the migration of three head and neck cancer cell lines, of different origin and metastatic stages (SCC-9, FADU, and Detroit 562), toward LECs and vice versa was investigated. Among the three cell lines, SCC9 was found to show significantly higher migration $(P \leq 0.0001)$ in response to LECs, followed by FADU $(P \leq 0.001)$ and then Detroit $562(P \leq 0.01)$ (Figure $1 \mathrm{~A})$. LECs also migrated significantly more toward SCC-9 $(P \leq 0.001)$, which was 1.89 -fold compared with control and 1.4-fold toward Detroit $562(P \leq 0.05)$ (Figure 1B). LECs did not show significant increase in migration toward FADU compared with the corresponding control (Figure 1B). These results indicate that among the three head and neck cancer cells studied, the interaction between SCC- 9 and LEC was more pronounced. Furthermore, SCC-9 is a squamous carcinoma line that is representative of $>90 \%$ of head and neck cancer types. Hence, for analysis of detailed molecular pathways that mediate LEC-tumor interactions, this study focused primarily on SCC-9. To understand the chemokine-chemokine receptor interactions involved in this process, PCR analysis of chemokine receptors expressed by SCC-9 cells treated with LEC conditioned medium was performed (Figure 1C). LEC-CM treatment significantly increased the mRNA expressions of $C C R 7(P \leq 0.01), C C R 8$ $(P \leq 0.05)$, and $C X C R 3(P \leq 0.01)$ in SCC-9 cells; and maximum increase was observed in CXCR3 levels (2.19-fold compared with control) (Figure 1C).

\section{$\mathrm{CF}_{3}$ DODA-Me Inhibits Proliferation and Tumor-Promoting Pathways in HNSCC Cells}

$\mathrm{CF}_{3}$ DODA-Me, exhibits potent anticancer activities ${ }^{24}$ and was investigated for its effects on proliferation and migration of SCC-9 cells. Treatment with $\mathrm{CF}_{3}$ DODA-Me significantly inhibited proliferation of SCC-9 cells at all the concentrations tested $(1,2$, and $5 \mu \mathrm{mol} / \mathrm{L}$ ) (Figure 1D). On the other hand, both LEC-CM and LPS-LEC-CM induced significant proliferation compared with control $(20 \%$ and $41.6 \%$ increase compared with control, respectively). This observed increase was also significantly inhibited by treatment with $\mathrm{CF}_{3}$ DODA-Me (Figure 1E). However, the inhibition in proliferation by the highest concentration of $\mathrm{CF}_{3}$ DODA-Me $(5 \mu \mathrm{mol} / \mathrm{L})$ was less pronounced than that observed in tumor cells directly treated with $\mathrm{CF}_{3} \mathrm{DODA}-\mathrm{Me}$ (72\% decreased proliferation observed in SCC-9 cells alone compared with the $32 \%$ and $23 \%$ decrease in SCC-9 cells treated with LEC-CM and LPS-LEC-CM, respectively, after treatment). In addition, an XTT [2,3-Bis-(2-Methoxy-4nitro-5-sulfophenyl)-2H-tetrazolium-5-carboxanilide, disodium salt] assay was also performed to measure changes in cell proliferation, which corroborates the data above (data not shown). $\mathrm{CF}_{3}$ DODA-Me at 2 and $5 \mu \mathrm{mol} / \mathrm{L}$ concentrations significantly increased annexin V-FITC positive SCC 9 cells $(80 \%$ and $71 \%$, respectively), indicating that the compound induced apoptosis of the tumor cells (Figure 1F). LEC-CM or LPS-LEC-CM treatment alone did not affect apoptosis of SCC-9 cells; however, $\mathrm{CF}_{3}$ DODA-Me significantly induced apoptosis even after addition of LEC-CM or LPS-LEC-CM in the HNSCC cells with the $5 \mu \mathrm{mol} / \mathrm{L}$ concentration, resulting in $44 \%$ and $49 \%$ of cells staining with annexin $\mathrm{V}$, respectively (Figure $1 \mathrm{G}$ ).

Next, its effect on cancer cell migration were studied. Cells were pretreated with the compound and placed in $8-\mu \mathrm{m}$ pore size PTE inserts and migration was followed for 24 hours (Figure $1 \mathrm{H}$ ). Treatment with $\mathrm{CF}_{3}$ DODA-Me significantly decreased migration of SCC-9 cells at all concentrations tested: $1 \mu \mathrm{mol} / \mathrm{L}(P \leq 0.001)$ and 2 and $5 \mu \mathrm{mol} / \mathrm{L}$ $(P \leq 0.0001)$ (Figure $1 \mathrm{H})$. Because remodeling of the extracellular matrix is an important event in early tumor 
metastasis and promotes migration, the effects of $\mathrm{CF}_{3}$ DODA-Me on expression of several MMPs that play important roles in the invasion and metastasis of HNSCC and directly modulate angiogenesis and tumor-induced lymphangiogenesis were analyzed. ${ }^{30} \mathrm{CF}_{3}$ DODA-Me significantly inhibited expression of several MMP mRNAs, including $M M P 2, M M P 7, M M P 9, M M P 11$, and $M M P 21$ (Figure 1I). In addition, $\mathrm{CF}_{3} \mathrm{DODA}-\mathrm{Me}$ decreased the expression of several chemokine receptors that were induced in the HNSCC cells in response to LEC-CM, such as CCR7, CCR1, CXCR3, and CXCR7 (Figure 1J). This demonstrates that $\mathrm{CF}_{3} \mathrm{DODA}-\mathrm{Me}$ suppresses chemokine-mediated tumorlymphatic interactions and suppresses several matrix remodeling genes that promote tumor migration.

\section{$\mathrm{CF}_{3}$ DODA-Me Alters HNSCC Cellular Bioenergetics and Decreases Metabolic Potential of HNSCC Cells}

As it is well established that the basal requirement of cancer cells to proliferate relies on energy production, some of the observed changes in proliferation could also be due to changes to metabolic activity of the tumor cells. To determine whether $\mathrm{CF}_{3}$ DODA-Me mediated the antiproliferative effect by altering tumor metabolism and cellular bioenergetics of SCC-9 cells, the Seahorse Cell Energy Phenotype assay was performed (Figure 2). In this assay, $\mathrm{CF}_{3} \mathrm{DODA}-\mathrm{Me}-$ mediated changes in metabolic potential of SCC-9 cells were followed by focusing on two major energy producing pathways, mitochondrial respiration and glycolytic pathway, via measuring OCR and ECAR, respectively, calculating the specific rates after injection of oligomycin (ATP synthase inhibitor) and FCCP (uncoupler of mitochondrial oxidative phosphorylation) in real time. The Seahorse assay medium was supplemented with glucose and glutamine. Interestingly, the OCR associated with the basal respiration of SCC-9 cells increased significantly when primed with inflamed LEC-CM $(P \leq 0.01)$ (Figure $2 \mathrm{~A})$. $\mathrm{CF}_{3}$ DODA-Me treatment of control or LPS-LEC-CM primed SCC-9 cells significantly decreased the OCR associated with the basal respiration ( $P \leq 0.0001$ or $P \leq 0.05$, respectively). However, it was not effective in decreasing the basal respiration of LEC-CM primed SCC-9 cells. The maximal respiration after FCCP injection of LPS-LEC-CM primed SCC-9 cells increased significantly compared with the control SCC-9 cells $(P \leq 0.05) . \mathrm{CF}_{3}$ DODA-Me treatment significantly reduced the maximal respiration of control SCC-9 cells $(P \leq 0.0001)$ as well as LEC-CM or LPSLEC-CM treated SCC-9 cells $(P \leq 0.0001)$.

Priming of SCC-9 cells with LEC-CM or inflamed LEC-CM did not alter the ECAR of SCC-9 cells (Figure 2B). $\mathrm{CF}_{3}$ DODA-Me treatment significantly increased the baseline ECAR in control as well as LPS-LEC-CM primed SCC-9 cells (Figure 2B). This indicated the compound's ability to increase the glycolytic rate of cells. After oligomycin injection, the ECAR of control or LEC-CM/LPS-LEC-CM primed SCC-9 cells significantly increased compared with their respective baseline ECAR. This denotes that priming of SCC-9 cells with LEC-CM/LPS-LEC-CM increases the maximal glycolytic capacity of SCC-9 cells. $\mathrm{CF}_{3}$ DODA-Me treatment inhibited this increase in ECAR in the control LECCM or LPS-LEC-CM primed SCC-9 cells (Figure 2B). However, $\mathrm{CF}_{3}$ DODA-Me treatment did not alter the maximal glycolytic capacity associated ECAR in the control or LEC-CM or LPS-LEC-CM primed SCC-9 cells (Figure 2B). Figure 2C depicts the overall changes in metabolic potential under the different treatment conditions. Under stressed condition, the compound significantly decreased the metabolic potential at $5 \mu \mathrm{mol} / \mathrm{L}$ concentration in control SCC-9 cells $(P \leq 0.0001)$ as well as in LEC-CM $(P \leq 0.01)$ or LPS-LEC-CM $(P \leq 0.001)$ primed cells (Figure $2 \mathrm{C}$ ). These results suggest that the drug $\mathrm{CF}_{3}$ DODA-Me alters metabolism of HNSCC cells through activating glycolytic pathway while reducing mitochondrial respiratory pathway.

\section{Inflamed LECs Cause Increased Migration of HNSCC} Cells and Induce Several Inflammatory Cytokines and Chemokines that Mediate Tumor-LEC Cross Talk

During inflammation, LECs produce several chemokines and cytokines that promote leukocyte entry and modulate the process of inflammation. ${ }^{31,32}$ Cancer cells hijack several of those same pathways by expressing cognate receptors or ligands to enter the lymphatics. ${ }^{10}$ We hypothesized that a bidirectional cross talk between LECs and tumor cells promotes tumor lymph node dissemination in HNSCC and that these mechanisms are more pronounced during inflammation. To investigate how LECs impact the migratory behavior of SCC-9 cells, we tested how conditioned medium from inflamed and noninflamed LECs modified the migration of SCC-9 cells. LECs that were inflamed significantly induced migration of the cancer cells, compared with the LECs alone, and $\mathrm{CF}_{3}$ DODA-Me significantly suppressed this LEC-induced increase in tumor cell migration $(P \leq 0.0001)$ (Figure 3A). To identify the potential factors that are important to increase proliferation and migration of SCC-9 cells in the presence of inflamed LECs, we analyzed the expression of specific chemokine receptors in normal versus LPS-LEC-CM treated SCC-9 cells and the effect of $\mathrm{CF}_{3}$ DODA-Me on these using real-time PCR (Figure 3B). The mRNA levels of chemokine receptors CXCR3 $(P \leq 0.01)$ and $C X C R 7$ and $C C R 7(P \leq 0.01)$ were increased in inflamed LEC-CM treated SCC-9 cells; and levels of $C X C R 3(P \leq 0.0001), C X C R 7(P \leq 0.001)$, and $C C R 7(P \leq 0.01$ and $P \leq 0.05)$ mRNA were decreased after treatment with $\mathrm{CF}_{3}$ DODA-Me.

Oncogenic mechanisms regulating AKT and ERK mediated pathways within tumor cells also contribute to tumor invasion and chemoresistance in multiple tumor types. ${ }^{33}$ Hence, we investigated the effects of $\mathrm{CF}_{3}$ DODA-Me on 

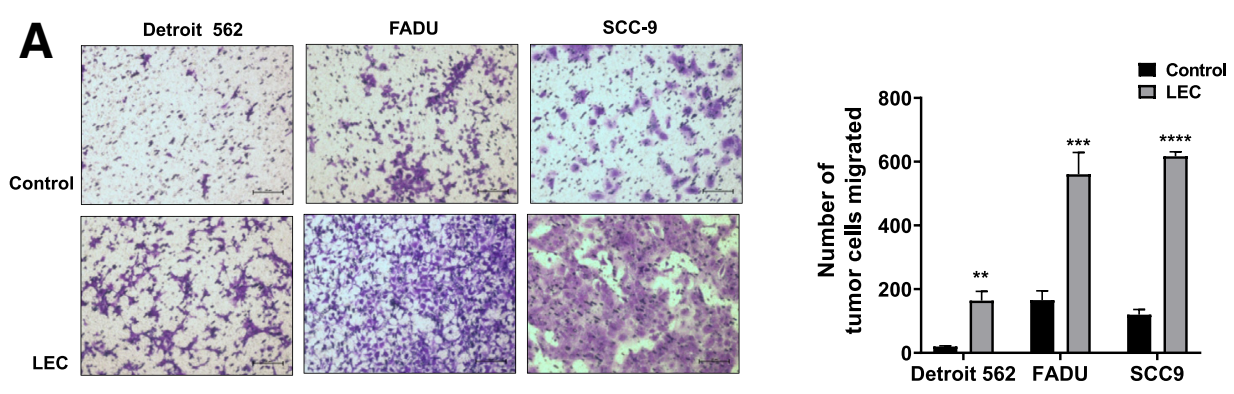

B

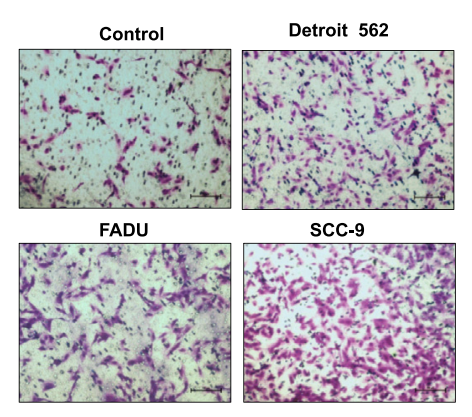

E

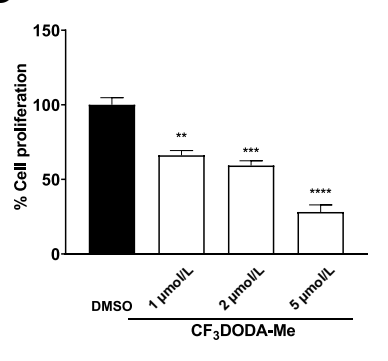

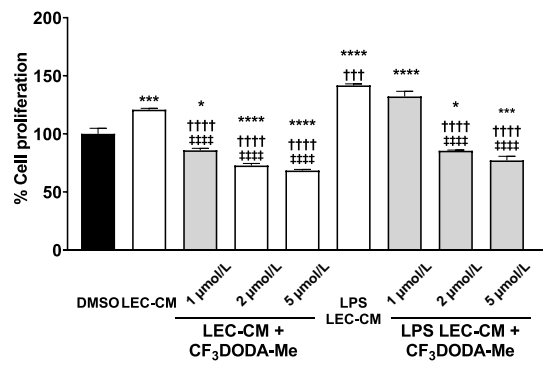

C
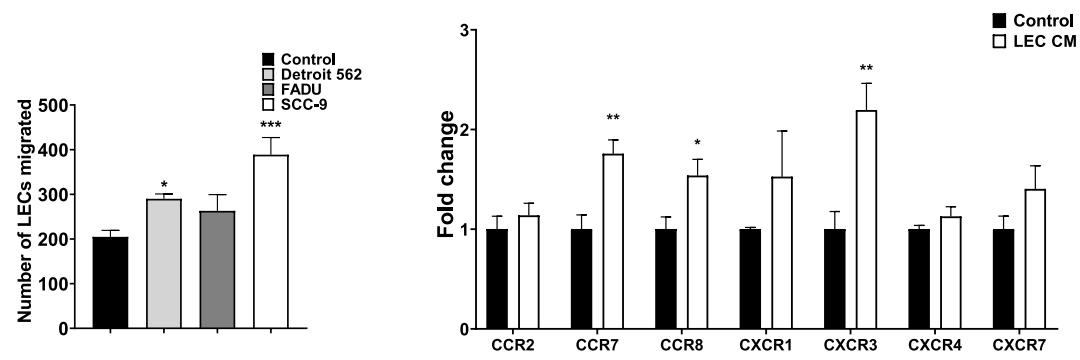

$\mathbf{F}$

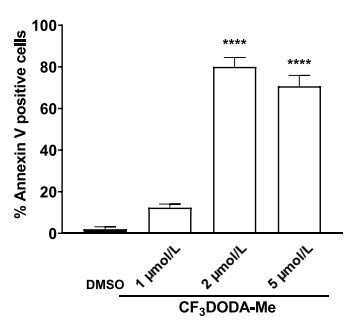

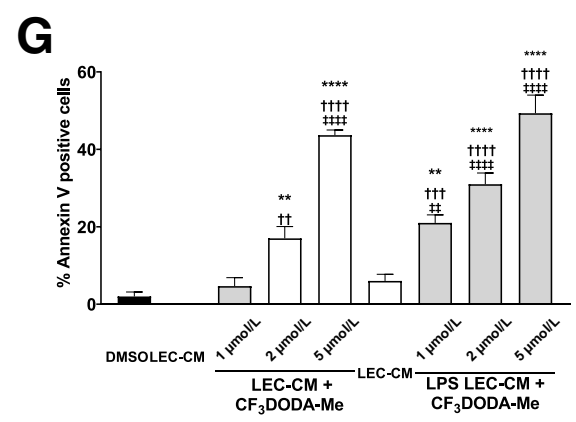

H Control complete DMEM CF DODA-Me (1 $\mu \mathrm{mol} / \mathrm{L})$

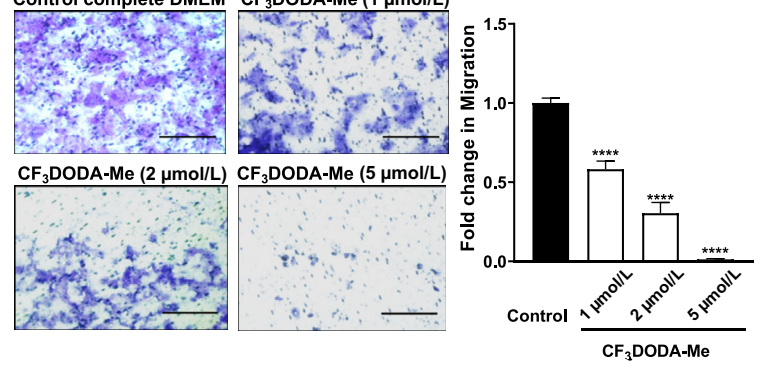

I

J
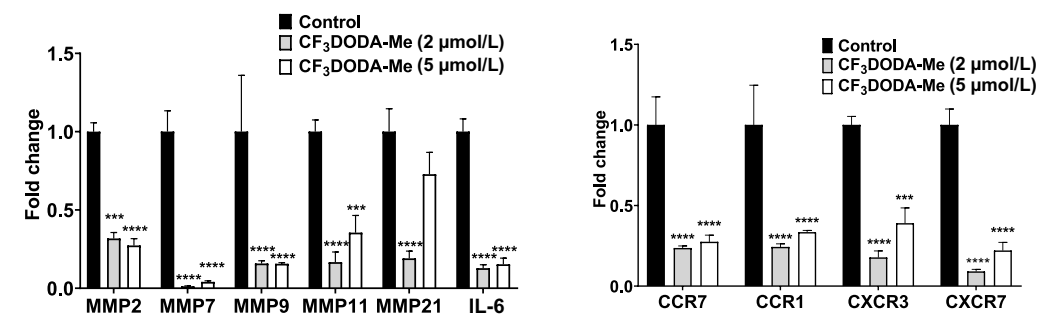
expression of phosphorylated AKT and p-ERK in HNSCC tumor cells in both the presence and the absence of LPSLEC-CM (Figure 3, C and D). The expression of p-ERK and phosphorylated AKT significantly decreased after treatment of cells with $\mathrm{CF}_{3}$ DODA-Me. In the presence of LPSLEC-CM, an increase in p-STAT-3 levels was observed. However, the levels of phosphorylated AKT and p-ERK were not increased. Interestingly, the compound was not as effective in reducing the expression of these proteins in SCC9 cells treated with LPS-LEC-CM in contrast to their effects in control SCC-9 cells (Figure 3D).

\section{CXCL9/10/11-CXCR3 Axis Is Induced in Inflamed LECS along with Other Tumor Modulatory Cytokines}

To determine some of the molecular factors that potentially mediate the increased proliferation and migration of SCC-9 cells in the presence of inflamed LECs, the gene expression of specific chemokines and cytokines in inflamed versus normal LECs was analyzed. Interestingly, LPS significantly induced the mRNA levels of chemokines in LECs by severalfold, particularly the CXCR3 ligands CXCL9 $(P \leq 0.001), C X C L 10(P \leq 0.01)$, and $C X C L 11(P \leq 0.01)$. LPS also increased expression of cytokines $I L I B$ $(P \leq 0.01)$, IL8 $(P \leq 0.05)$, IL6 $(P \leq 0.05)$, and $C C L 2 /$ $M C P 1 \quad(P \leq 0.01)$ (Figure $4 \mathrm{~A}$ ), whereas $2 \mu \mathrm{mol} / \mathrm{L}$ $\mathrm{CF}_{3} \mathrm{DODA}-\mathrm{Me}$ significantly decreased inflammationmediated activation of these cytokines and chemokines.

As LPS induced CXCL9, CXCL10, and CXCL11 in LECs, the induction of JAK/STAT in these cells was further studied, as STAT-3 has been reported to be involved in CXCL11 production. ${ }^{34}$ LPS significantly increased p-STAT-3 $(P \leq 0.01) . \mathrm{CF}_{3}$ DODA-Me significantly decreased the LPSinduced levels of p-JAK-2 $(P \leq 0.01, P \leq 0.001$, and $P \leq 0.0001$ for 1,2 , and $5 \mu \mathrm{mol} / \mathrm{L}$ concentrations, respectively) and p-STAT-3 ( $P \leq 0.01$ for all three doses $)$ (Figure 4B).

Because tumor cells produce several chemotactic and lymphangiogenic molecules that increase LEC migration, we investigated how LECs migrated in response to SCC-9 cells (Figure 4C). LEC invasion toward SCC-9 cells was significantly higher than in response to the medium alone $(P \leq 0.0001)$. However, this was decreased when tumor cells were pretreated with $1 \mu \mathrm{mol} / \mathrm{L}(P \leq 0.01), 2 \mu \mathrm{mol} / \mathrm{L}$ $(P \leq 0.001)$, and $5 \mu \mathrm{mol} / \mathrm{L}(P \leq 0.0001)$ of $\mathrm{CF}_{3}$ DODA-Me.

\section{CXCR3-CXCL11 Axis Promotes Tumor Cell Migration toward Inflamed Lymphatic Endothelium and Activation of Tumor-Promoting Signaling Pathways}

Our results clearly demonstrate that LPS dramatically induced expression of CXCL9, CXCL10, and CXCL11 in LECs, and treatment of SCC-9 cells with LPS-LEC-CM increased $C X C R 3$ expression, in the tumor cells. CXCR3, a seven-transmembrane G-protein-coupled receptor, binds with CXCL9 [monokine induced by IFN-gamma (MIG)], CXCL10 [IFN-induced protein 10kDa (IP10)], and CXCL11 [interferon-inducible T-cell alpha chemoattractant (I-TAC)]. CXCR3 gene expression is induced in several tumors and regulates migration of tumor cells; furthermore, increased levels of CXCR3 correlate with poor prognosis in breast, melanoma, renal, and colon cancer patients. ${ }^{35}$ Among the three CXCR3 ligands, CXCL11 exhibits the highest affinity for CXCR3. ${ }^{36,37}$

To confirm that CXCL11 levels were increased in LECs in response to inflammation and conditioned medium from cancer cells, culture supernatants were collected from LECs treated with LPS and CM from different HNSCC lines (SCC9-CM, FADU-CM, and Detroit 562-CM) and ELISA assays were performed. As shown in Figure 5A, exposure to LPS significantly induced levels of CXCL11 produced by LECs (2105 pg/mL). CM from all the HNSCC lines, SCC-9, FADU, and Detroit 562, also significantly enhanced CXCL11 levels $(1145,1174$, and $544 \mathrm{pg} / \mathrm{mL}$, respectively, indicating this mechanism is common to all cancer cell lines tested). In the untreated controls, no detectable level of CXCL11 was obtained. To clearly establish the role of CXCL11 as a chemotactic agent for HNSCC tumor cells, the effect of CXCL11 recombinant protein on SCC-9 migration was studied. Interestingly, CXCL11 significantly increased SCC-9 cell migration $(P \leq 0.05)$ toward medium supplemented with recombinant CXCL11 (Figure 5B). Further corroborating the importance of this axis in tumor-lymphatic interactions, this chemoattraction was found to be

\footnotetext{
Figure 1 Head and neck squamous cell carcinoma (HNSCC) cells show increased migration in response to lymphatic endothelial cells (LECs), and several key tumorpromoting pathways are inhibited by methyl 2-trifluoromethyl-3,11-dioxoolean-1,12-dien-30-oate ( $\left.\mathrm{CF}_{3} \mathrm{DODA}-\mathrm{Me}\right)$. A: Detroit 562, FADU, and SCC-9 cells were allowed to migrate toward LECS. In control groups, the cells were allowed to migrate toward LEC medium-endothelial growth medium containing $3 \%$ fetal bovine serum (FBS). Number of cells migrated is plotted. B: LECs were allowed to migrate toward Detroit 562, FADU, and SCC-9 cells or endothelial growth medium containing $3 \%$ FBS. Number of cells migrated is plotted. C: Relative mRNA expression of chemokine receptors in SCC-9 cells primed with LEC conditioned medium was analyzed using realtime PCR. D-I: Novel triterpenoid $\mathrm{CF}_{3}$ DODA-Me inhibits HNSCC proliferation and migration. D: SCC-9 cells were treated with 1, 2, and $5 \mu \mathrm{mol} / \mathrm{L}$ of CF 3 DODA-Me for 24 hours, trypsinized, counted, and represented as percentage cell proliferation. E: Cells were treated with LEC conditioned medium (LEC-CM) or LPS-LEC-CM and then with 1,2 , and $5 \mu \mathrm{mol} / \mathrm{L}$ of $\mathrm{CF}_{3} \mathrm{DODA}-\mathrm{Me}$ for 24 hours, trypsinized, counted, and represented as percentage cell proliferation counted. F: SCC-9 cells were treated with 1,2 , or $5 \mu \mathrm{mol} / \mathrm{L}$ of $\mathrm{CF}_{3}$ DODA-Me, and annexin V apoptotic assay was performed. G: Cells were treated with LEC-CM or LPS-LEC-CM and then treated with 1, 2, or $5 \mu$ mol/L of $\mathrm{CF}_{3} \mathrm{DODA}-\mathrm{Me}$, and annexin $\mathrm{V}$ apoptotic assay was performed. H: For testing migration, SCC-9 cells were grown in 6 -well plate and treated with 1, 2, and $5 \mu$ mol/L

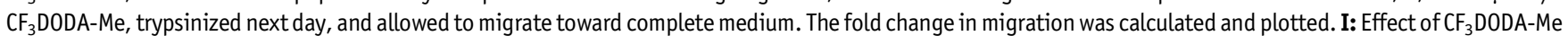
on matrix remodeling-associated gene expression. J: Effect of $\mathrm{CF}_{3}$ DODA-Me on expression of chemokine receptors in SCC-9 cells was analyzed using real-time PCR. Data are expressed as means \pm SEM $(\mathbf{A}-\mathbf{G}, \mathbf{I}$, and $\mathbf{J}){ }^{*} P<0.05,{ }^{* *} P<0.01,{ }^{* * *} P<0.001$, and ${ }^{* * * *} P<0.0001$ versus control; ${ }^{\dagger \dagger} P<0.01,{ }^{\dagger \dagger \dagger} P<0.001$, and ${ }^{\dagger \dagger \dagger \dagger} P<0.0001$ versus LEC-CM; ${ }^{\ddagger \ddagger} P<0.01,{ }^{\ddagger \ddagger \ddagger} P<0.0001$ versus LPS-LEC-CM. Scale bars $=100 \mu \mathrm{m}$ (A, B, and $\left.\mathbf{H}\right)$. Original magnification, $\times 10$ (A, B, and H). DMEM, Dulbecco's modified Eagle's medium; DMSO, dimethyl sulfoxide; MMP, matrix metalloproteinase.
} 

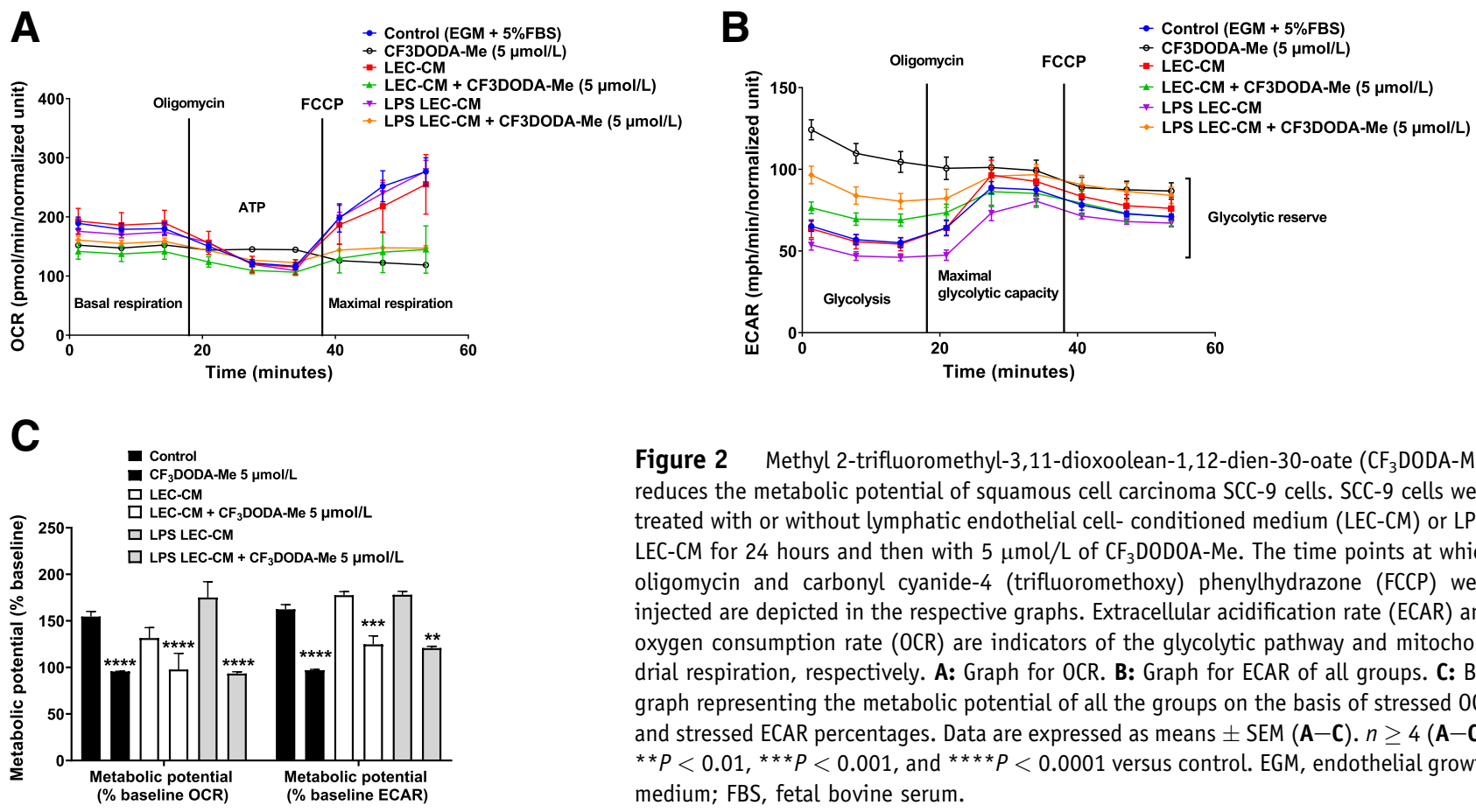

Figure 2 Methyl 2-trifluoromethyl-3,11-dioxoolean-1,12-dien-30-oate $\left(\mathrm{CF}_{3} \mathrm{DODA}-\mathrm{Me}\right)$ reduces the metabolic potential of squamous cell carcinoma SCC-9 cells. SCC-9 cells were treated with or without lymphatic endothelial cell- conditioned medium (LEC-CM) or LPSLEC-CM for 24 hours and then with $5 \mu \mathrm{mol} / \mathrm{L}$ of $\mathrm{CF}_{3}$ DODOA-Me. The time points at which oligomycin and carbonyl cyanide-4 (trifluoromethoxy) phenylhydrazone (FCCP) were injected are depicted in the respective graphs. Extracellular acidification rate (ECAR) and oxygen consumption rate (OCR) are indicators of the glycolytic pathway and mitochondrial respiration, respectively. A: Graph for OCR. B: Graph for ECAR of all groups. C: Bar graph representing the metabolic potential of all the groups on the basis of stressed OCR and stressed ECAR percentages. Data are expressed as means \pm SEM $(\mathbf{A}-\mathbf{C}) . n \geq 4(\mathbf{A}-\mathbf{C})$. ${ }^{* *} P<0.01,{ }^{* * *} P<0.001$, and $* * * * P<0.0001$ versus control. EGM, endothelial growth medium; FBS, fetal bovine serum.

significantly reduced when SCC-9 cells were pretreated with CXCR3 inhibitor, AMG487.

To further confirm that CXCL11-CXCR3 axis plays a critical role in migration of HNSCC cells toward LECs in response to inflammation, a neutralizing antibody against CXCL11 in LPS-primed LECs was used to deplete CXCL11 levels, block CXCR3 expression in SCC-9 cells, and analyze tumor migration under different conditions. Migration of control SCC-9 cells toward inflamed LECs pretreated with CXCL11 neutralizing antibody and with CXCR3 blocked SCC-9 cells moving toward inflamed LECs was carefully evaluated. Figure 5C shows that depleting CXCL11 production from LECs significantly diminished migration of the HNSCC cells $(P \leq 0.01)$. Inhibition of CXCR3 by using a pharmacologic inhibitor (AMG487) also caused a significant decrease in tumor cell migration. Tumor cell migration toward inflamed LECs was significantly inhibited when this axis was completely blocked (Figure 5C). LPS was also added to the medium alone and did not have any direct effect on tumor cell migration (data not shown), further indicating that inflammatory stimuli in the tumor microenvironment facilitate tumor-lymphatic cross talk by altering the expression of specific cytokines, such as CXCL11 in LECs and its cognate receptor CXCR3 in the tumor cells.

\section{CXCL11 Activates Tumor-Promoting Endothelial Mesenchymal Transition and JAK/STAT Pathways in Head and Neck Cancer Cells}

During early metastasis, carcinoma cells detach from the primary tumor and invade through the basement membrane and the tumor cells undergo EMTs. ${ }^{38}$ Because CXCL11 induces migration of tumor cells, the effect of CXCL11 on expression of genes associated with matrix remodeling and EMT was determined. CXCL11 treatment significantly increased the mRNA levels of $I L 6(P \leq 0.05)$ and $I L 1 B$ $(P \leq 0.01)$ (Figure 5D), and there was no increase in levels of $C X C R 3$ or $C X C R 7$ mRNAs. Consistent with previous data on $\mathrm{CF}_{3}$ DODA-Me treatment in SCC-9 cells and inflamed LECs (Figures 1, I and J, 3B, and 4A), $\mathrm{CF}_{3}$ DODA-Me significantly reduced expression of the chemokine receptors and cytokine levels. Treatment with recombinant CXCL11 protein increased the expression of $M M P 7(P \leq 0.05)$ and $M M P 9(P \leq 0.001)$ (Figure $5 \mathrm{E})$ but not $M M P 2, M M P 11, M M P 12$, or $M M P 21$, whereas $\mathrm{CF}_{3}$ DODA-Me significantly decreased all the MMPs, except MMP12 levels. To determine whether increased cell migration induced by CXCL11 was associated with activation of EMT in HNSCC tumor cells, a panel of EMT markers was evaluated by quantitative real-time PCR (Figure 5F). CXCL11 significantly induced PTCH1 ( $P \leq 0.0001)$, GLII $(P \leq 0.05)$,VIMI $(P \leq 0.01)$, and TWIST2 $(P \leq 0.05)$ mRNA levels, and a trend toward increased expression was observed for TWISTI and SNAI2 (not significant).

Because CXCL11-CXCR3 axis activates STAT-3, ${ }^{39}$ JAK/STAT as well as p-ERK protein levels that regulate both tumor-promoting and tumor-migration pathways were also analyzed (Figure 5G). Western blot analysis corroborated our findings, and CXCL11 was found to increase the levels of p-JAK-2 $(P \leq 0.05)$ and p-STAT-3 $(P \leq 0.0001)$ in SCC-9 cells; and $\mathrm{CF}_{3}$ DODA-Me significantly reduced levels of p-STAT-3, p-JAK-2, and p-ERK. 
A
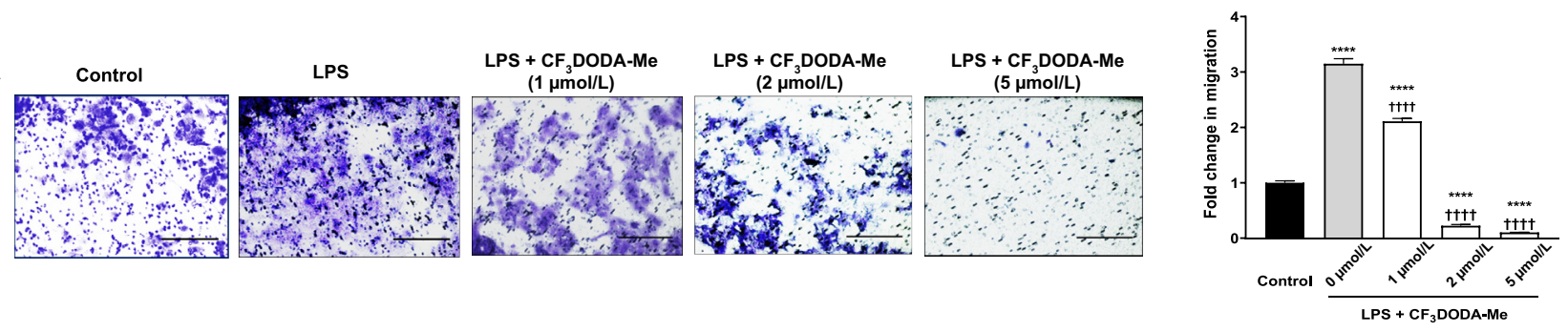

B
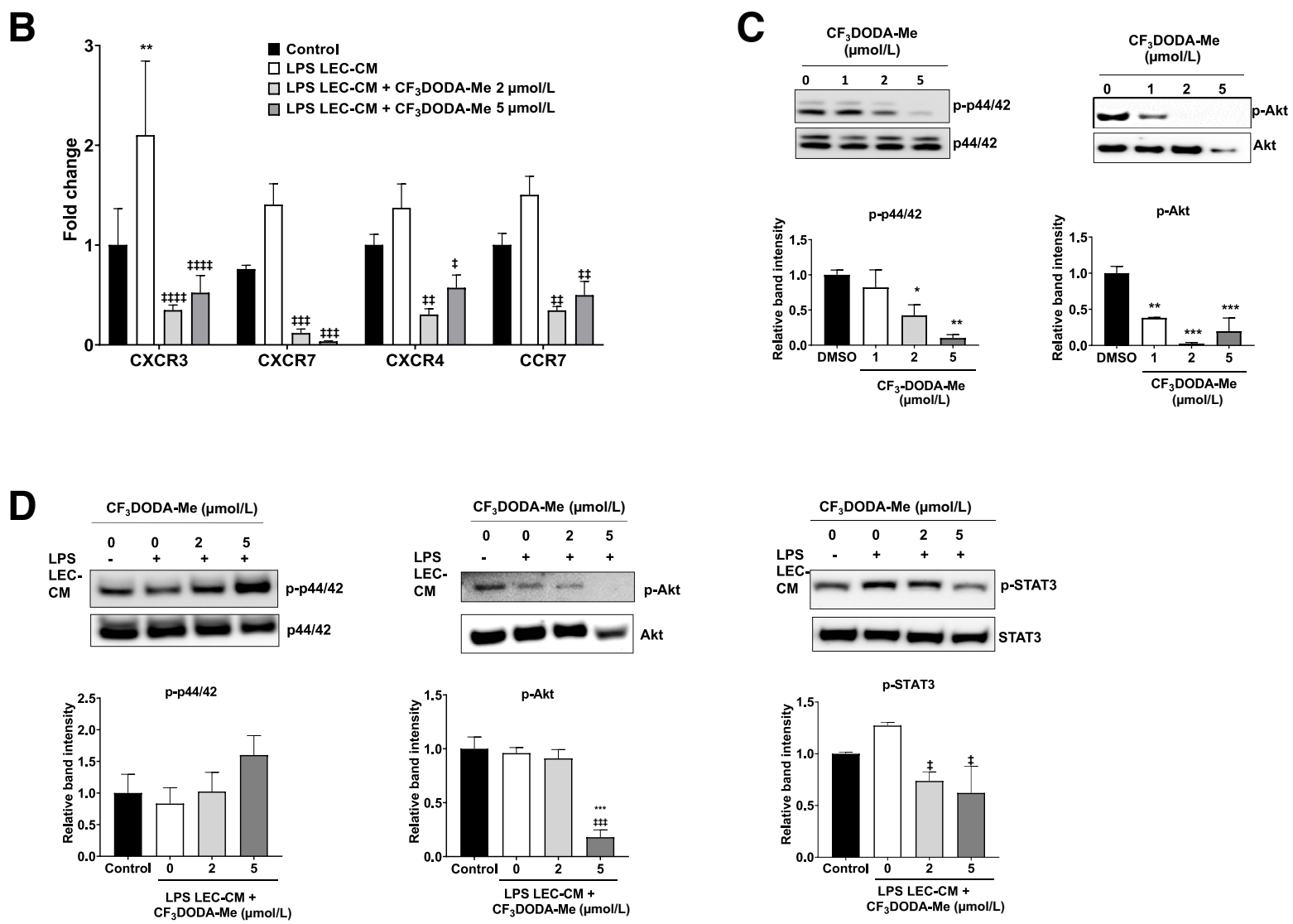

Figure 3 Inflamed lymphatic endothelial cells (LECS) potentiate increased migration and active cytokine and chemokine production in tumor cells. A: Squamous cell carcinoma SCC-9 cells were treated with 1, 2, and $5 \mu \mathrm{mol} / \mathrm{L}$ of methyl 2-trifluoromethyl-3,11-dioxoolean-1,12-dien-30-oate (CF $\left.\mathrm{DODA}_{3}-\mathrm{Me}\right)$ and were allowed to migrate toward LECs. The fold change in migration was calculated and plotted. B: SCC-9 cells were treated with LPS-lymphatic endothelial cellconditioned medium (LPS-LEC-CM) and with $\mathrm{CF}_{3}$ DODA-Me for 24 hours, and mRNA levels of inflammatory cytokines and chemokine receptors were analyzed using PCR. C: SCC-9 cells were treated with 1, 2, or $5 \mu \mathrm{mol} / \mathrm{L}$ of $\mathrm{CF}_{3} \mathrm{DODA}-\mathrm{Me}$, and the protein levels of phosphorylated p44/42 (p-p44/42) and phosphorylated AKT (p-AKT) were analyzed using Western blot analysis. Relative expression levels of p-p44/42/p44/42 and p-AKT/AKT were quantified and plotted. D: SCC-9 cells were treated with LPS-LEC-CM and with 2 or $5 \mu \mathrm{mol} / \mathrm{L} \mathrm{CF}_{3}$ DODA-Me, and the protein levels of p-p44/42, p-AKT, and phosphorylated STAT-3 (p-STAT-3) were analyzed using Western blot analysis. Relative expression levels of p-p44/42/p44/42, p-AKT/AKT, and p-STAT-3/STAT-3 were quantified and plotted. Data are expressed as means \pm SEM $($ A-D $) .{ }^{*} P<0.05,{ }^{*} P<<0.01,{ }^{* *} P<0.001$, and ${ }^{* * * *} P<0.0001$ versus control; ${ }^{\dagger} P<0.05,{ }^{\dagger \dagger} P<0.01,{ }^{\dagger \dagger \dagger} P<0.001$, and ${ }_{\dagger \dagger t \dagger} P<0.0001$ versus LPS LECS; ${ }^{\ddagger} P<0.05,{ }^{\ddagger \ddagger} P<0.01,{ }^{\ddagger \ddagger \ddagger} P<0.001$, and ${ }^{\ddagger \ddagger \ddagger \ddagger} P<0.0001$ versus LPS LEC-CM. Scale bars $=100 \mu \mathrm{m}$ (A). Original magnification, $\times 10$ (A). DMSO, dimethyl sulfoxide.

\section{CXCR3 Expression Is 0verexpressed in HNSCC Patient Tumors and Is Significantly Associated with Lymph Node Invasion and Advanced Tumor Stage}

To validate our findings in clinical patient samples, the expression of CXCR3 and podoplanin (a lymphatic vessel-specific marker), was analyzed in paraffin-embedded human head and neck tumor array samples by immunohistochemistry (Figure 6, A-L). Analysis of the tissue array showed increased CXCR3 expression in 45 of 70 of the HNSCC samples at variable levels of intensity (Figure 6, A-D) compared with the normal tissues (Figure 6, E and F). There was also an increased expression of podoplanin in the head and neck cancer cores (Figure 6, G-J) compared with the normal tissue sections (Figure 6, K and L), indicating increased lymphatic infiltration in the tumor samples. 


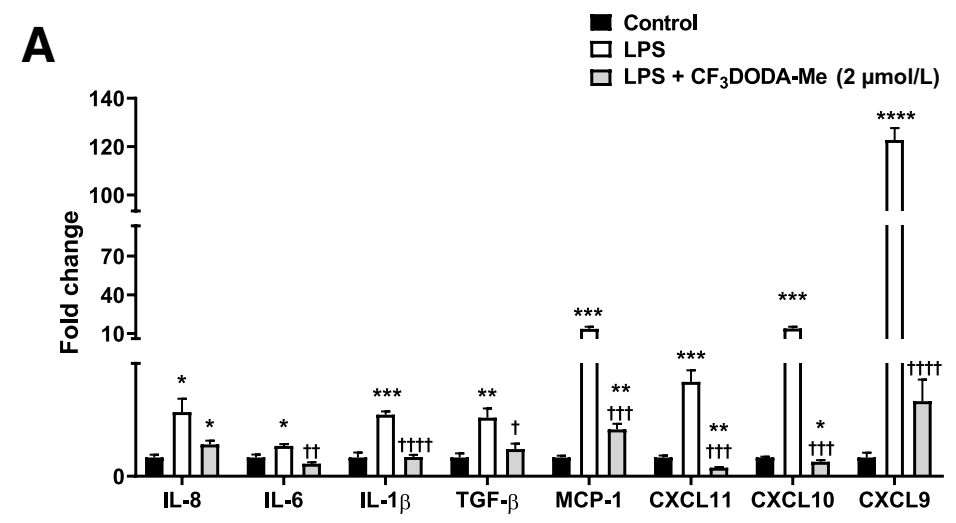

B
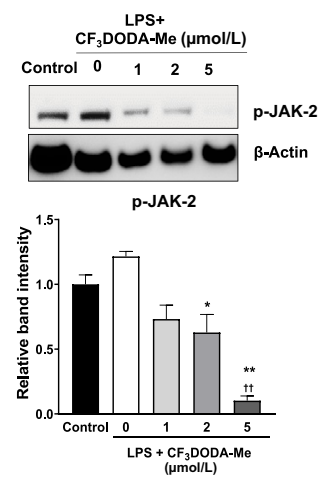
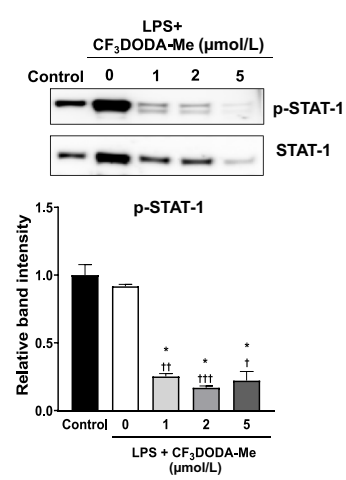
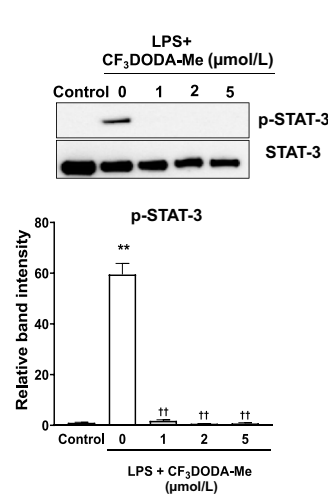

Figure 4 Inflammation also promotes cytokine and chemokine production in lymphatic endothelial cells (LECS) and activates proinflammatory tumorpromoting pathways A: Inflammation induces expression of various cytokines and chemokines in LECS. LECs were primed with LPS and then treated with methyl 2-trifluoromethyl-3,11-dioxoolean-1,12-dien30-oate $\left(\mathrm{CF}_{3} \mathrm{DODA}-\mathrm{Me}\right)$. mRNA levels of inflammatory cytokines and chemokines were analyzed using realtime PCR. B: Janus kinase (JAK)/signal transducer and activator of transcription (STAT) pathway is induced in LECs inflamed with LPS. LECs were primed with LPS and then treated with 1,2 , or $5 \mu \mathrm{mol} / \mathrm{L}$ of $\mathrm{CF}_{3}$ DODA-Me. Protein levels of phosphorylated JAK-2 ( $p-J A K-2)$, phosphorylated STAT-1 ( $p-S T A T-1)$, and phosphorylated STAT-3 (p-STAT-3) were analyzed by Western blot analysis. Relative expression levels of $p$ JAK-2/ $\beta$-actin, p-STAT-1/STAT-1, and p-STAT-3/STAT3 were quantified and plotted. C: Migration of LECS toward squamous cell carcinoma SCC-9 cells. LECs were allowed to migrate toward SCC-9 cells treated with 1 , 2 , or $5 \mu \mathrm{mol} / \mathrm{L}_{\text {of }} \mathrm{CF}_{3} \mathrm{DODA}-\mathrm{Me}$. Representative images of migrated LECs are shown. The fold change in migration was calculated and plotted. Data are expressed as means \pm SEM $(\mathbf{A}-\mathbf{C})$. ${ }^{*} P<0.05$, ${ }^{* *} P<0.01,{ }^{* * *} P<0.001$, and ${ }^{* * * *} P<0.0001$ versus control; ${ }^{\dagger} P<0.05,{ }^{\dagger \dagger} P<0.01,{ }^{\dagger \dagger} P<0.001$, and ${ }^{\dagger \dagger \dagger \dagger} P<0.0001$ versus LPS; ${ }^{\ddagger} P<0.01$ ${ }_{\ddagger \ddagger \ddagger} P<0.001$, and ${ }^{\ddagger \ddagger \ddagger \ddagger} P<0.0001$ versus SCC -9 . Scale bars $=100 \mu \mathrm{m}(\mathbf{C})$. Original magnification, $\times 10(\mathbf{C})$. EGM, endothelial growth medium; MCP1, monocyte chemoattractant protein 1 ; TGF- $\beta$, transforming growth factor- $\beta$.
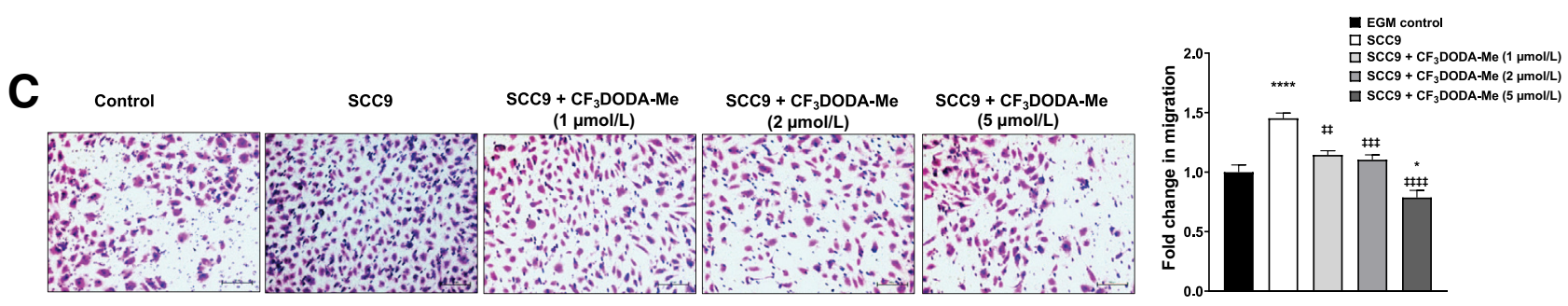

To determine any correlation between CXCR3, lymphovascular invasion, and pathologic stage, RNA-sequencing and pathologic data available for 448 subjects were downloaded from TCGA database. The distribution of the gene expression (RNA sequencing) for CXCR3 was analyzed using a multinomial logistic model to the stage variable using CXCR3 expression, age of diagnosis, and sex as covariates. A likelihood ratio test was then performed, and with $P=0.006$, the null hypothesis that CXCR3 has no effect on the stages was rejected. There was a significant effect of CXCR3 on the tumor stage at the $1 \%$ level $(P<0.01)$. Figure $6, \mathrm{M}$ and $\mathrm{N}$, shows the boxplot of the gene expression for the different categories of LNM. The boxplots are based on $n=332$ HNSCC patients (with combined stages III and IV), and whose LNM status was available in the database. Among these patients, 92 had no LNM, whereas 240 had positive LNM. CXCR3 expression and LNM were found to be significantly associated $(P<0.05)$ among the combined stages III and IV patients ( $n=332$ ). Furthermore, age shows statistically significant association at the 5\% level, whereas sex shows no significant association (data not shown).

\section{Discussion}

Results of this study indicate that that CXCR3-CXCL11 axis plays an important role in promoting tumor-lymphatic cross talk in an inflammatory environment. Furthermore, the study data clearly demonstrate that $\mathrm{CF}_{3}$ DODA-Me inhibits the CXCR3-CXCL11 axis on both tumor cells and inflamed LECs while also significantly inhibiting several tumorpromoting pathways. Tumor cells are able to form a prometastatic niche within the lymph node and remain dormant within draining lymph nodes, even after resection of the primary tumor. ${ }^{40}$ Hence, targeting cancer cells at sites of entry to lymphatic vessels forms an attractive means for 
A

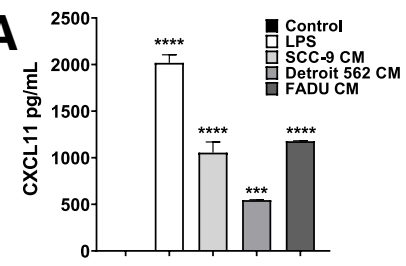

B

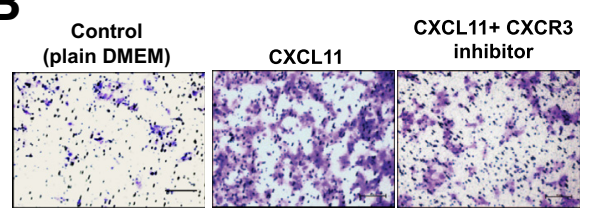

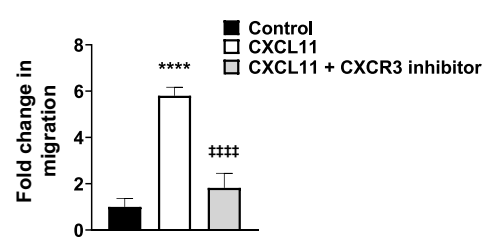

C
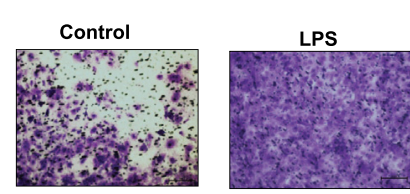

LPS + CXCR3
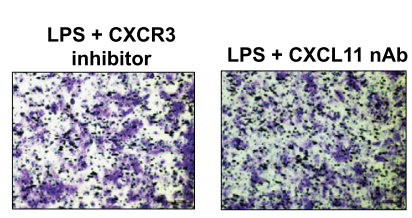

LPS
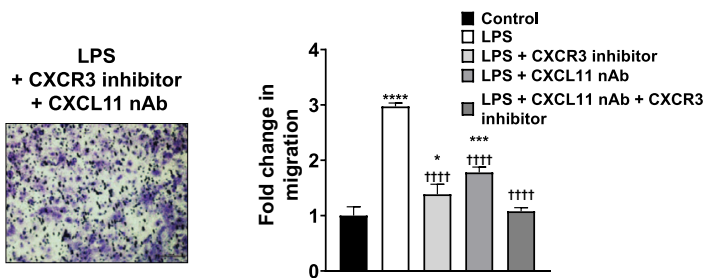

D

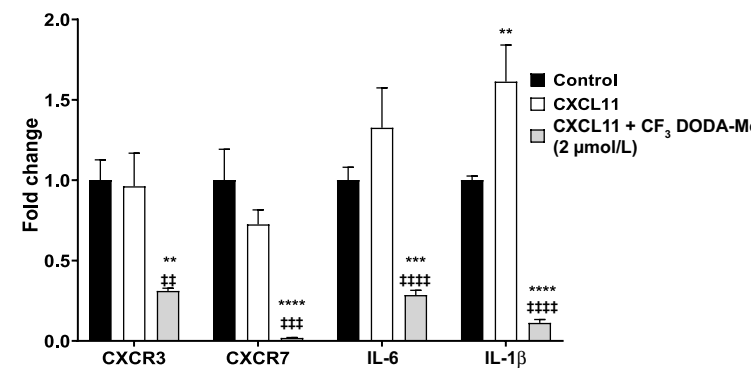

E

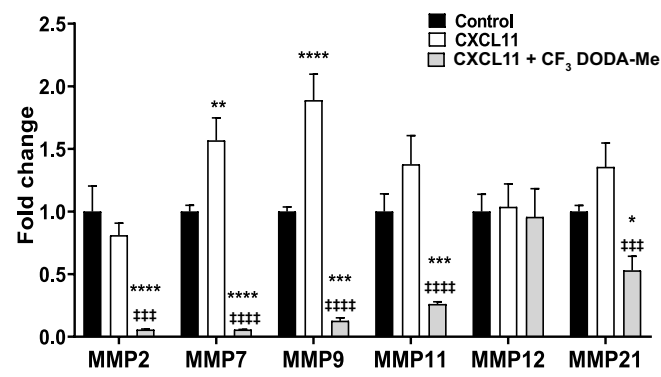

$\mathbf{F}$

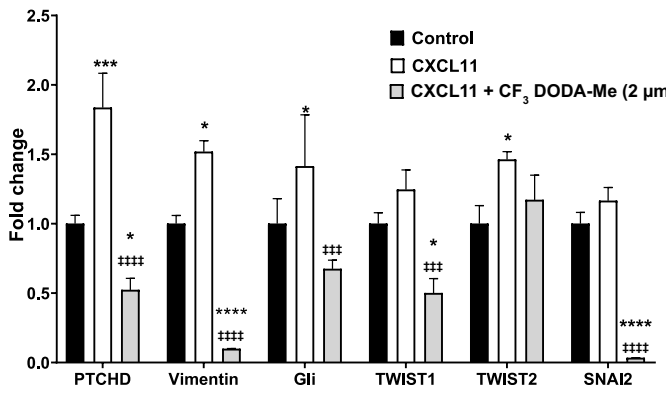

Figure 5 Chemokine (C-X-C motif) ligand 11 (CXCL11) induces migration and expression of epithelial-mesenchymal transition (EMT) related markers in squamous cell carcinoma SCC-9 cells. A: CXCL11 levels are significantly induced in lymphatic endothelial cells-conditioned medium (LEC-CM) in response to inflammatory stimuli. Enzyme-linked immunosorbent assays for CXCL11 chemokine in conditioned medium from control LECs (endothelial growth medium $+5 \%$ fetal bovine serum) and LECs treated with LPS $(100 \mathrm{ng} / \mathrm{mL})$ and SCC-9, FADU, and Detroit 562 cancer cells CM. B: CXCL11 recombinant protein induced migration of SCC-9 cells. Migration of SCC-9 control cells toward plain Dulbecco's modified Eagle's medium (DMEM) and CXCL11 recombinant protein $(100 \mathrm{ng} / \mathrm{mL})$. Migration of CXCR3 inhibitor, AMG487 $(1 \mu \mathrm{mol} / \mathrm{L})$, pretreated SCC-9 cells toward CXCL11 recombinant protein $(100 \mathrm{ng} / \mathrm{mL})$. Representative images are shown. The fold change in migration was calculated and plotted. C: SCC-9 migration toward LPS primed LECS was reduced in the presence of CXCR3 inhibitor or XXCL11 neutralizing antibodies (nAbs). Migration of SCC-9 control cells toward LECs, LPS + LECs, and LPS + LECs + CXCL11 nAb $(1 \mu \mathrm{g} / \mathrm{mL})$. Migration of SCC- 9 cells treated with $1 \mu \mathrm{mol} / \mathrm{L}$ of CXCR3 inhibitor, AMG487, toward LPS + LECs or LPS + LECS + CXCL11 nAb. Representative images are shown. The fold change in migration was calculated and plotted. D-F: Expression of chemokines and matrix remodeling and EMT related genes in CXCL11 treated SCC-9 cells. SCC-9 cells were treated with CXCL11 recombinant protein and then with $2 \mu \mathrm{mol} / \mathrm{L}$ of $\mathrm{CF}_{3}$ DODA-Me. D-F: mRNA expression levels of various chemokine receptors (D), matrix remodeling associated genes (E), and EMT associated genes (F) were analyzed using PCR. G: CXCL11 treatment increased JAK-STAT expression in SCC-9 cells. SCC-9 cells were treated with CXCL11 recombinant protein and then with 2 and $5 \mu \mathrm{mol} / \mathrm{L}$ of $\mathrm{CF}_{3}$ DODA-Me. Protein levels of phosphorylated STAT-3 (p-STAT-3), phosphorylated JAK-2 (p-JAK-2), and phosphorylated $p 44 / 42(p-p 44 / 42)$ were analyzed by Western blot analysis. Relative expression levels of $p$-STAT-3/STAT-3, p-JAK-2/ $\beta$-actin, and p44/42/p44/42 and were quantified and plotted. Data are expressed as means \pm SEM $(\mathbf{A}-\mathbf{G}) .{ }^{*} P<0.05$, ${ }^{* *} P<0.01,{ }^{* * *} P<0.001$, and ${ }^{* * * *} P<0.0001$ versus control; ${ }^{\dagger} P<0.01$, ${ }^{\dagger \dagger \dagger} P<0.001$, and ${ }^{\dagger \dagger \dagger \dagger} P<0.0001$ versus LPS LECs; ${ }^{\ddagger \ddagger \ddagger} P<0.001,{ }^{\ddagger \ddagger \ddagger \ddagger} P<0.0001$ versus CXCL11 recombinant protein. Scale bars $=100 \mu \mathrm{m}(\mathbf{B}$ and $\mathbf{C})$. Original magnification, $\times 10(\mathbf{B}$ and $\mathbf{C})$. MMP, matrix metalloproteinase.
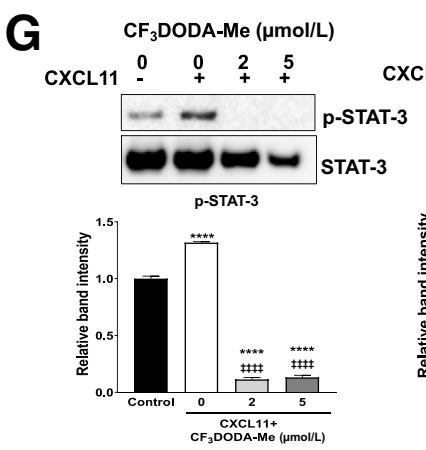

$\mathrm{CF}_{3} \mathrm{DODA}-\mathrm{Me}(\mu \mathrm{mol} / \mathrm{L})$

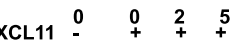
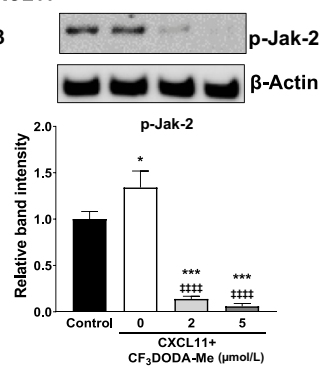

$\mathrm{CF}_{3} \mathrm{DODA}-\mathrm{Me}(\mu \mathrm{mol} / \mathrm{L})$
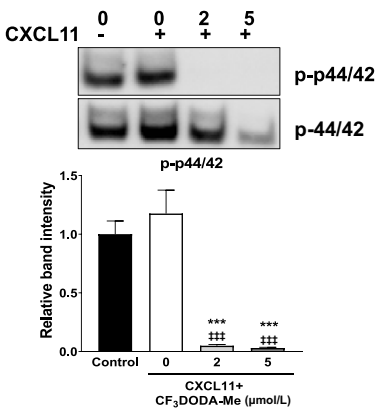

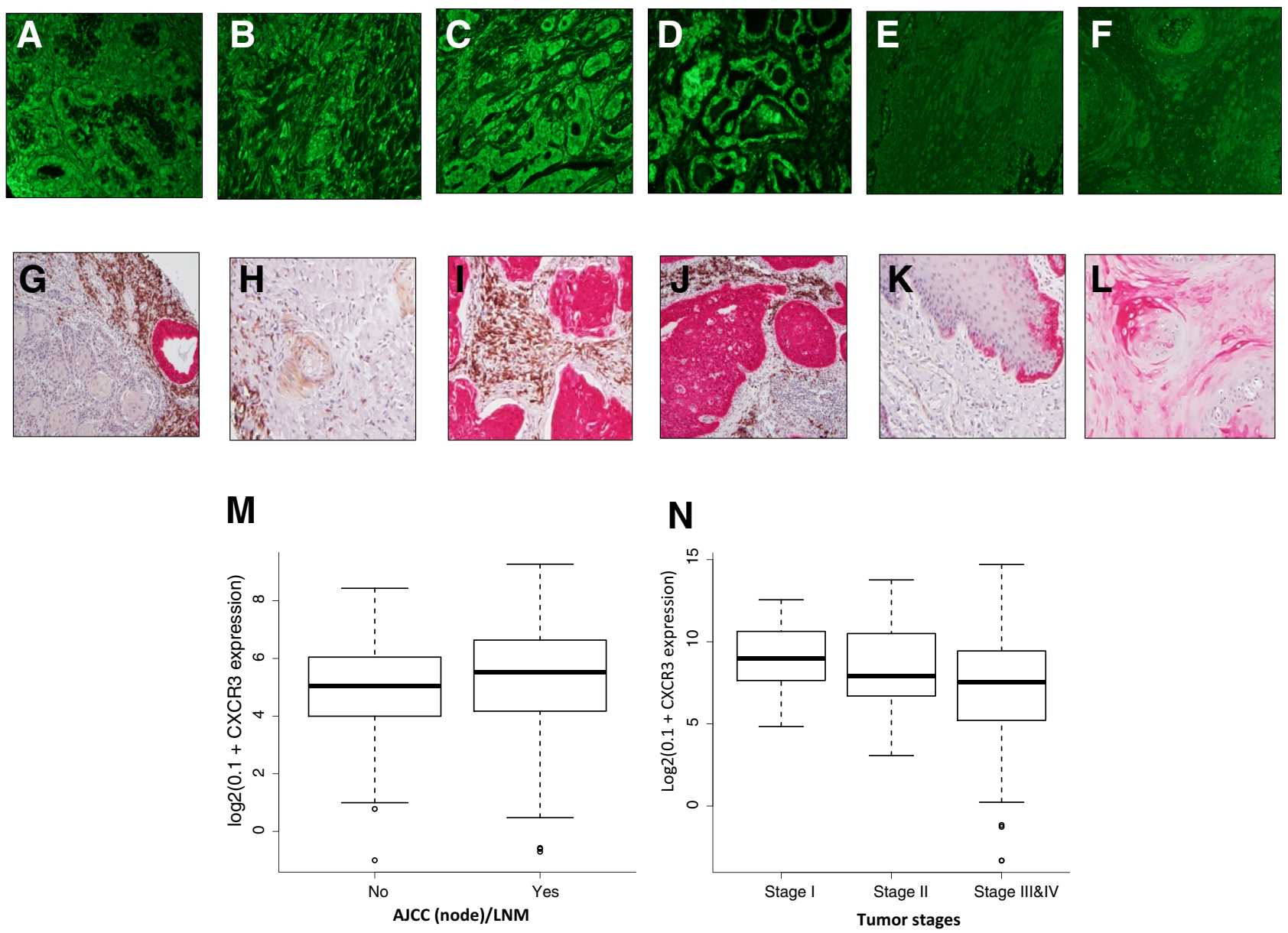

Figure 6 Chemokine (C-X-C motif) receptor 3 (CXCR3) shows increased expression in head and neck tumor arrays and is associated with lymph node invasion in head and neck squamous cell carcinomas (HNSCC) patients. A-F: Representative immunohistochemistry images of CXCR3 expression (detected using Alexa Fluor 488 fluorescent secondary antibody) in paraffin-embedded sections of head and neck cancer patients (A-D) and in normal head and neck tissue sections (E and $\mathbf{F}$ ). G-L: Representative immunohistochemistry images of podoplanin expression (brown) and cytokeratin 19 (pink) expression in head and neck cancer patients $(\mathbf{G}-\mathbf{J})$ and in normal tissues (K and $\mathbf{L})$. M: Box plots showing CXCR3 association with lymph node metastasis in HNSCC patients, as analyzed from The Cancer Genome Atlas (TGCA) database. N: Box plots showing CXCR3 association with lymph node metastasis (LNM) and tumor stages in HNSCC patients, as analyzed from TGCA database. Original magnification, $\times 20(\mathbf{A}-\mathbf{L})$. AJCC, American Joint Committee on Cancer.

therapeutic interventions. However, only a few studies have investigated the role of inflamed lymphatic microenvironment and the direct interactions between LECs and tumor cells that guide early tumor entry and migration. ${ }^{41}$

Toll-like receptor 4 receptors are highly expressed in HNSCC tumors and cell lines, and toll-like receptor 4 activation with its agonist LPS increases tumor growth, cell migration, and proliferation. ${ }^{42}$ LPS also significantly affects inflammatory mechanisms in the lymphatic bed. ${ }^{23}$ Hence, LPS was used as the primary mediator of inflammation in these studies. HNSCCs are characterized by early lymphatic metastasis, and this often precludes conventional chemotherapy. ${ }^{43}$ Pentacyclic triterpenoids, such as methyl 2-cyano-3,12-dioxooleana-1,9-dien-28-oate (bardoxolone $\mathrm{Me})$, are potent anticancer agents and $\mathrm{CF}_{3}$ DODA-Me was recently identified as a novel bardoxolone $\mathrm{Me}$ analog that may have reduced toxic adverse effects. ${ }^{44}$ In the present study, $\mathrm{CF}_{3} \mathrm{DODA}-\mathrm{Me}$ decreased HNSCC cell proliferation.
It also induced apoptosis, as previously documented in other cancers. $^{24,44}$ HNSCC cell proliferation was, however, induced on stimulation with LEC-CM or LPS-LEC-CM, possibly because of the increased cytokines and chemokines secreted by LECs (Figure 1, C and E) that affect cell proliferative pathways. This could further explain the reduced effectiveness of $\mathrm{CF}_{3}$ DODA-Me in inhibiting LECCM primed SCC-9 cell proliferation compared with its direct effects on these tumor cells. It is possible that the changes observed in proliferation in the presence of LPS-LEC-CM and/or the compound $\mathrm{CF}_{3}$ DODA-Me are due to changes in metabolism of the tumor cells. Several compounds have been shown to induce cancer cell death via targeting mitochondrial metabolism and inhibiting the Warburg effect. ${ }^{26,45}$ These results demonstrate that $\mathrm{CF}_{3}$ DODA-Me treatment effectively reduced the OCR associated with basal as well as maximal respiration. It also increased the glycolysis-associated ECAR but did not alter 


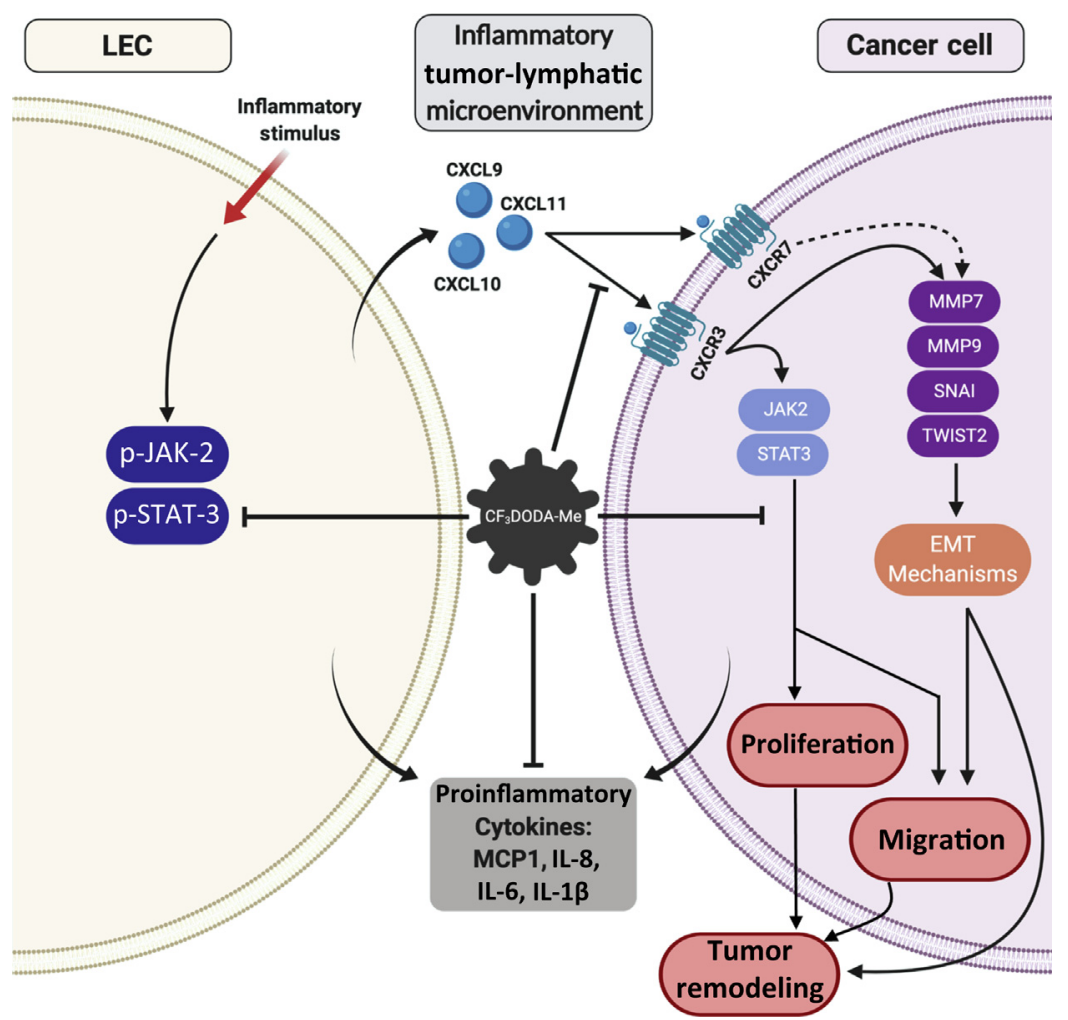

Figure 7 Schematic representation of inflammationmediated tumor-lymphatic cross talk in head and neck squamous cell carcinomas (HNSCC). On inflammatory stimulation, such as with LPS, lymphatic endothelial cells (LECS) expressed increased levels of several cytokines, such as IL-8, IL-6, MCP1, and IL-1 $\beta$, and the chemokines chemokine (C-X-C motif) ligand CXCL10, CXCL9, and CXCL11, directly triggering mechanisms that activate tumor cell proliferation and migration. Enhanced expression of CXCL11 by inflamed LECs and chemokine (C-X-C motif) receptor 3 (CXCR3) expressed by LEC conditioned tumor cells activate the Janus kinase (JAK)/signal transducer and activator of transcription 3 (STAT-3) signaling mechanisms that further promote tumor progression. In addition, the metabolic potential of the tumor cells is enhanced in the presence of inflamed LECs and could further contribute to tumor progression in an inflammatory microenvironment. HNSCC tumor cells in response to CXCL11 treatment activate matrix remodeling and epithelial-to-mesenchymal transition (EMT) mechanisms that are key steps necessary for early metastasis. Methyl 2-trifluoromethyl-3,11-dioxoolean-1,12-dien-30-oate ( $\left.\mathrm{CF}_{3} \mathrm{DODA}-\mathrm{Me}\right)$ was found to effectively suppress several of these tumor-promoting events by either directly targeting tumor cells or modulating the response of tumor cells to inflamed LECs and could be a potential therapeutic target. JAK2, Janus kinase 2; MMP, matrix metalloproteinase; MCP1, monocyte chemoattractant protein 1; p-JAK-2, phosphorylated JAK-2; p-STAT-3, phosphorylated STAT-3. the maximal glycolytic capacity-associated ECAR of SCC9 cells treated with or without LPS-LEC-CM. This indicates the potency of compound to inhibit aerobic glycolysis of SCC-9 cells and can be correlated to the apoptotic and antiproliferative effects (Figure 1, E-G). Also, this is the first study to clearly demonstrate that on stimulation with LEC-CM or LPS-LEC-CM, there was a significant increase in the metabolic potential of the tumor cells. This could also explain some of the tumor-promoting effects seen with LEC-CM or LPS-LEC-CM.

The migration and chemoattraction of LECs and HNSCC cells were found to be most pronounced for SCC9, a squamous carcinoma cell line. This is significant as SCC accounts for $90 \%$ of all HNSCC tumor types. Hence, the molecular cues or chemoattractants that mediate this process were investigated. This study focused on the CXCR3-CXCL9/10/11 axis, which has been significantly implicated in both mediating immune responses and as a viable cancer target. ${ }^{15}$ CXCR3 is differentially activated by CXCL9, CXCL10, and CXCL11; however, CXCL11 has the highest affinity to CXCR3. ${ }^{37}$ Decreased levels of CXCL11 reduce tumor cell growth and metastasis in vivo. ${ }^{46}$ CXCR3-CXCL11 axis in particular mediates macrophage recruitment and hence could further contribute to the activation of the inflammatory microenvironment. ${ }^{47}$ A constitutive activation of the JAK/STAT pathway was observed in the LECs, which is consistent with previous reports that the CXCL9/10/11-CXCR3 induces STAT and phosphatidylinositol 3-kinase-AKT signaling. ${ }^{48}$ Hence, these results lead us to speculate that, in response to specific signals from the surrounding microenvironment, particularly from inflamed LECs near the primary tumor, there is activation of oncogenic pathways that further promote tumor progression.

CXCL11, produced by the LECs, may attract tumor cells toward the lymphatic endothelium and promote tumor entry and migration. This is supported by the study data showing that soluble CXCL11 promotes tumor chemotaxis. Furthermore, conditioned medium from a panel of HNSCC lines (SCC-9, Detroit, and FADU) significantly enhanced CXCL11 levels produced by LECs, indicating it is a key component of tumor-lymphatic cross talk. Inhibition of CXCR3 on HNSCC cells diminished the tumor migration to LECs, underlining the important role of the CXCR3CXCL11 axis. CXCL11 was also found to induce the activation of several MMPs and EMT-associated genes in the HNSCC cells. Cancer progression involves overexpression of MMPs that mediate many of the changes in the tumor-microenvironment associated with angiogenic or lymphangiogenic processes. $\mathrm{CF}_{3} \mathrm{DODA}-\mathrm{Me}$ significantly suppressed several of these MMPs in the HNSCC tumor cells, thereby initiating an antimetastatic switch. Concomitantly, CXCL11 specifically induced levels of MMP7 and $M M P 9$. This is interesting because $M M P 9$ modulates bioavailability of vascular endothelial growth factor and may directly affect tumor-induced lymphangiogenesis. ${ }^{30}$ 
MMP7 also promotes tumor migration and invasion. ${ }^{49}$ In addition, CXCL11 also increased the expression of TWIST2, GLII, PTCHI, and SNAI2, thereby activating the EMT program in the SCC-9 cells. EMT is critical for early metastasis, is often induced by inflammation, and endows tumor cells with enhanced migratory and invasive properties. ${ }^{50}$ CXCL11 is reported to promote EMT in ovarian cancer cells by inducing levels of SNAI2 and SNAII. ${ }^{51}$ Interestingly, $\mathrm{CF}_{3} \mathrm{DODA}-\mathrm{Me}$ did not suppress TWIST2 induced in response to CXCL11 in HNSCC cells, whereas it significantly suppressed many of the other inducers.

These results also indicate that p-JAK-2 and p-STAT-3 are induced in response to both LEC-CM and CXCL11 in the HNSCC cells. The JAK-STAT-3 signaling pathway is linked to tumor proliferation, migration, and invasion and can also regulate MMP-9 and MMP-7 expression. ${ }^{19}$ As shown in the schematic (Figure 7), our data support the concept that chemotactic signals from inflamed LECs, such as CXCL11, induce activation of the JAK-STAT and AKT pathways. This, in turn, increases tumor cell proliferation and activation of MMP- and EMT-mediated pathways to enhance tumor migration (Figure 7). Also, although $\mathrm{CF}_{3}$ DODA-Me exhibited potent anticancer activities and significantly inhibited several of the molecular pathways involved in the tumor-lymphatic cross talk, it was not able to completely abrogate some of the oncogenic pathways activated in response to tumor growth-promoting cues from the inflamed lymphatic endothelium. This could explain why tumors exhibit differential drug resistance.

Overexpression of CXCR3 in HNSCC patient tumor sections, combined with significant increase in lymphatic infiltration in the tumor samples, also underlines the importance of the tumor-lymphatic signaling axis we have outlined. These findings are further corroborated by analysis of HNSCC patient gene expression and clinical data from TCGA database that establish a significant correlation between increased CXCR3 expression and lymphovascular invasion in HNSCC with advanced tumor stage. This suggests that CXCR3 should be explored as a potential therapeutic target for lymphatic metastasis in HNSCC.

Thus, results from this study demonstrate that enhanced signaling through the CXCL11-CXCR3 axis promoted HNSCC chemotaxis toward LECs by activating cell proliferation pathways, remodeling the extracellular matrix, and inducing EMT-associated transcription factors (Figure 7). Stimulation with LEC-CM enhanced tumor metabolism and glycolytic respiration in addition to enhancing several tumor-promoting pathways. The novel triterpenoid compound, $\mathrm{CF}_{3} \mathrm{DODA}-\mathrm{Me}$, was effective in altering cell proliferation, migration, cellular bioenergetics, and mitochondrial function in the tumor cells and abrogated several of the key pathways mediating a tumor-lymphatic cross talk. Hence, it could be an effective anticancer agent to target tumor cells at sites of metastasis and inhibit tumor progression through lymphatics.

\section{Acknowledgments}

We thank Cassidy Weeks and Saurabh Dhole for technical help.

\section{Author Contributions}

S.K. and S.C. designed the study; S.H.S. and S.G. contributed reagents; S.K., S.R., S.S., L.V., and T.K.W. performed experiments; S.K., S.R., S.S., L.V., T.K.W., and S.C. analyzed and interpreted the data; S.S. analyzed cancer database; S.K., S.G., S.H.S., and S.C. wrote the article.

\section{References}

1. Achen MG, Mann GB, Stacker SA: Targeting lymphangiogenesis to prevent tumour metastasis. Br J Cancer 2006, 94:1355-1360

2. Sood A, Wykes J, Roshan D, Wang LY, McGuinness J, Forstner D, Fowler A, Lee M, Kernohan M, Ngo Q, Estall V, Ebrahimi A: Number of nodal metastases and prognosis in metastatic cutaneous squamous cell carcinoma of the head and neck. ANZ J Surg 2019, 89:863-867

3. Argiris A, Karamouzis MV, Raben D, Ferris RL: Head and neck cancer. Lancet 2008, 371:1695-1709

4. Cho JK, Hyun SH, Choi N, Kim MJ, Padera TP, Choi JY, Jeong HS Significance of lymph node metastasis in cancer dissemination of head and neck cancer. Transl Oncol 2015, 8:119-125

5. Zhang Z, Helman JI, Li LJ: Lymphangiogenesis, lymphatic endothelial cells and lymphatic metastasis in head and neck cancer: a review of mechanisms. Int J Oral Sci 2010, 2:5-14

6. Maula SM, Luukkaa M, Grenman R, Jackson D, Jalkanen S, Ristamaki R: Intratumoral lymphatics are essential for the metastatic spread and prognosis in squamous cell carcinomas of the head and neck region. Cancer Res 2003, 63:1920-1926

7. Ma Q, Dieterich LC, Detmar M: Multiple roles of lymphatic vessels in tumor progression. Curr Opin Immunol 2018, 53:7-12

8. Pereira ER, Jones D, Jung K, Padera TP: The lymph node microenvironment and its role in the progression of metastatic cancer. Semin Cell Dev Biol 2015, 38:98-105

9. Zhuang Z, Jian P, Longjiang L, Bo H, Wenlin X: Altered phenotype of lymphatic endothelial cells induced by highly metastatic OTSCC cells contributed to the lymphatic metastasis of OTSCC cells. Cancer Sci 2010, 101:686-692

10. Lee E, Pandey NB, Popel AS: Crosstalk between cancer cells and blood endothelial and lymphatic endothelial cells in tumour and organ microenvironment. Expert Rev Mol Med 2015, 17:e3

11. Pereira ER, Kedrin D, Seano G, Gautier O, Meijer EFJ, Jones D, Chin SM, Kitahara S, Bouta EM, Chang J, Beech E, Jeong HS, Carroll MC, Taghian AG, Padera TP: Lymph node metastases can invade local blood vessels, exit the node, and colonize distant organs in mice. Science 2018, 359:1403-1407

12. Yeo KP, Angeli V: Bidirectional crosstalk between lymphatic endothelial cell and $\mathrm{T}$ cell and its implications in tumor immunity. Front Immunol 2017, 8:83

13. Das S, Sarrou E, Podgrabinska S, Cassella M, Mungamuri SK, Feirt N, Gordon R, Nagi CS, Wang Y, Entenberg D, Condeelis J, Skobe M: Tumor cell entry into the lymph node is controlled by CCL1 chemokine expressed by lymph node lymphatic sinuses. J Exp Med 2013, 210:1509-1528

14. Karaman S, Detmar M: Mechanisms of lymphatic metastasis. J Clin Invest 2014, 124:922-928

15. Tokunaga R, Zhang W, Naseem M, Puccini A, Berger MD, Soni S, McSkane M, Baba H, Lenz HJ: CXCL9, CXCL10, CXCL11/CXCR3 axis for immune activation: a target for novel cancer therapy. Cancer Treat Rev 2018, 63:40-47 
16. Skinner HD, Giri U, Yang LP, Kumar M, Liu Y, Story MD, Pickering CR, Byers LA, Williams MD, Wang J, Shen L, Yoo SY, Fan YH, Molkentine DP, Beadle BM, Meyn RE, Myers JN, Heymach JV: Integrative analysis identifies a novel AXL-PI3 kinasePD-L1 signaling axis associated with radiation resistance in head and neck cancer. Clin Cancer Res 2017, 23:2713-2722

17. Kozakiewicz P, Grzybowska-Szatkowska L: Application of molecular targeted therapies in the treatment of head and neck squamous cell carcinoma. Oncol Lett 2018, 15:7497-7505

18. Padera TP, Kuo AH, Hoshida T, Liao S, Lobo J, Kozak KR, Fukumura D, Jain RK: Differential response of primary tumor versus lymphatic metastasis to VEGFR-2 and VEGFR-3 kinase inhibitors cediranib and vandetanib. Mol Cancer Ther 2008, 7:2272-2279

19. Fulda S, Kroemer G: Targeting mitochondrial apoptosis by betulinic acid in human cancers. Drug Discov Today 2009, 14:885-890

20. Liby KT, Sporn MB: Synthetic oleanane triterpenoids: multifunctional drugs with a broad range of applications for prevention and treatment of chronic disease. Pharmacol Rev 2012, 64:972-1003

21. Safe S, Kasiappan R: Natural products as mechanism-based anticancer agents: Sp transcription factors as targets. Phytother Res 2016, 30:1723-1732

22. Chakraborty S, Zawieja DC, Davis MJ, Muthuchamy M: MicroRNA signature of inflamed lymphatic endothelium and role of miR-9 in lymphangiogenesis and inflammation. Am J Physiol Cell Physiol 2015, 309:C680-C692

23. Chakraborty S, Zawieja SD, Wang W, Lee Y, Wang YJ, von der Weid PY, Zawieja DC, Muthuchamy M: Lipopolysaccharide modulates neutrophil recruitment and macrophage polarization on lymphatic vessels and impairs lymphatic function in rat mesentery. Am J Physiol Heart Circ Physiol 2015, 309:H2042-H2057

24. Kasiappan R, Jutooru I, Mohankumar K, Karki K, Lacey A, Safe S: Reactive oxygen species (ROS)-inducing triterpenoid inhibits rhabdomyosarcoma cell and tumor growth through targeting $\mathrm{Sp}$ transcription factors. Mol Cancer Res 2019, 17:794-805

25. Hedrick E, Lee SO, Doddapaneni R, Singh M, Safe S: NR4A1 antagonists inhibit beta1-integrin-dependent breast cancer cell migration. Mol Cell Biol 2016, 36:1383-1394

26. Jan CI, Tsai MH, Chiu CF, Huang YP, Liu CJ, Chang NW: Fenofibrate suppresses oral tumorigenesis via reprogramming metabolic processes: potential drug repurposing for oral cancer. Int J Biol Sci 2016, 12:786-798

27. Lee Y, Chakraborty S, Meininger CJ, Muthuchamy M: Insulin resistance disrupts cell integrity, mitochondrial function, and inflammatory signaling in lymphatic endothelium. Microcirculation 2018, 25:e12492

28. Lanning NJ, Looyenga BD, Kauffman AL, Niemi NM, Sudderth J, DeBerardinis RJ, MacKeigan JP: A mitochondrial RNAi screen defines cellular bioenergetic determinants and identifies an adenylate kinase as a key regulator of ATP levels. Cell Rep 2014, 7:907-917

29. Mancinelli R, Onori P, Gaudio E, DeMorrow S, Franchitto A, Francis H, Glaser S, Carpino G, Venter J, Alvaro D, Kopriva S, White M, Kossie A, Savage J, Alpini G: Follicle-stimulating hormone increases cholangiocyte proliferation by an autocrine mechanism via cAMP-dependent phosphorylation of ERK1/2 and Elk-1. Am J Physiol Gastrointest Liver Physiol 2009, 297:G11-G26

30. Bergers G, Brekken R, McMahon G, Vu TH, Itoh T, Tamaki K, Tanzawa K, Thorpe P, Itohara S, Werb Z, Hanahan D: Matrix metalloproteinase-9 triggers the angiogenic switch during carcinogenesis. Nat Cell Biol 2000, 2:737-744

31. Shin K, Lee SH: Interplay between inflammatory responses and lymphatic vessels. Immune Netw 2014, 14:182-186

32. Johnson LA, Clasper S, Holt AP, Lalor PF, Baban D, Jackson DG: An inflammation-induced mechanism for leukocyte transmigration across lymphatic vessel endothelium. J Exp Med 2006, 203: $2763-2777$

33. Cao Z, Liao Q, Su M, Huang K, Jin J, Cao D: AKT and ERK dual inhibitors: the way forward? Cancer Lett 2019, 459:30-40

34. Yang CH, Wei L, Pfeffer SR, Du Z, Murti A, Valentine WJ, Zheng Y, Pfeffer LM: Identification of CXCL11 as a STAT3dependent gene induced by IFN. J Immunol 2007, 178:986-992

35. Ma B, Khazali A, Wells A: CXCR3 in carcinoma progression. Histol Histopathol 2015, 30:781-792

36. Tensen CP, Flier J, Van Der Raaij-Helmer EM, SampatSardjoepersad S, Van Der Schors RC, Leurs R, Scheper RJ, Boorsma DM, Willemze R: Human IP-9: a keratinocyte-derived high affinity CXC-chemokine ligand for the IP-10/Mig receptor (CXCR3). J Invest Dermatol 1999, 112:716-722

37. Cole KE, Strick CA, Paradis TJ, Ogborne KT, Loetscher M, Gladue RP, Lin W, Boyd JG, Moser B, Wood DE, Sahagan BG, Neote K: Interferon-inducible T cell alpha chemoattractant (I-TAC): a novel non-ELR CXC chemokine with potent activity on activated T cells through selective high affinity binding to CXCR3. J Exp Med 1998, 187:2009-2021

38. Yeung KT, Yang J: Epithelial-mesenchymal transition in tumor metastasis. Mol Oncol 2017, 11:28-39

39. Groom JR, Luster AD: CXCR3 ligands: redundant, collaborative and antagonistic functions. Immunol Cell Biol 2011, 89:207-215

40. Meier F, Will S, Ellwanger U, Schlagenhauff B, Schittek B, Rassner G, Garbe C: Metastatic pathways and time courses in the orderly progression of cutaneous melanoma. Br J Dermatol 2002, 147:62-70

41. Podgrabinska S, Skobe M: Role of lymphatic vasculature in regional and distant metastases. Microvasc Res 2014, 95:46-52

42. Zu Y, Ping W, Deng T, Zhang N, Fu X, Sun W: Lipopolysaccharideinduced toll-like receptor 4 signaling in esophageal squamous cell carcinoma promotes tumor proliferation and regulates inflammatory cytokines expression. Dis Esophagus 2017, 30:1-8

43. Allen CT, Law JH, Dunn GP, Uppaluri R: Emerging insights into head and neck cancer metastasis. Head Neck 2013, 35:1669-1678

44. Jin UH, Cheng Y, Zhou B, Safe S: Bardoxolone methyl and a related triterpenoid downregulate cMyc expression in leukemia cells. Mol Pharmacol 2017, 91:438-450

45. Roth KG, Mambetsariev I, Kulkarni P, Salgia R: The mitochondrion as an emerging therapeutic target in cancer. Trends Mol Med 2019, 26:119-134

46. Gao YJ, Liu L, Li S, Yuan GF, Li L, Zhu HY, Cao GY: Downregulation of CXCL11 inhibits colorectal cancer cell growth and epithelial-mesenchymal transition. Onco Targets Ther 2018, 11: 7333-7343

47. Torraca V, Cui C, Boland R, Bebelman JP, van der Sar AM, Smit MJ, Siderius M, Spaink HP, Meijer AH: The CXCR3-CXCL11 signaling axis mediates macrophage recruitment and dissemination of mycobacterial infection. Dis Model Mech 2015, 8:253-269

48. Zhang C, Li Z, Xu L, Che X, Wen T, Fan Y, Li C, Wang S, Cheng Y, Wang X, Qu X, Liu Y: CXCL9/10/11, a regulator of PD-L1 expression in gastric cancer. BMC Cancer 2018, 18:462

49. Basu S, Thorat R, Dalal SN: MMP7 is required to mediate cell invasion and tumor formation upon plakophilin3 loss. PLoS One 2015, 10:e123979

50. Suarez-Carmona M, Lesage J, Cataldo D, Gilles C: EMT and inflammation: inseparable actors of cancer progression. Mol Oncol 2017, 11:805-823

51. Benhadjeba S, Edjekouane L, Sauve K, Carmona E, Tremblay A: Feedback control of the CXCR7/CXCL11 chemokine axis by estrogen receptor alpha in ovarian cancer. Mol Oncol 2018, 12: $1689-1705$ 